\title{
Analysis of crystallographic preferred orientations of experimentally deformed Black Hills Quartzite
}

\author{
Rüdiger Kilian and Renée Heilbronner \\ Department of Environmental Sciences, Geological Institute, Bernoullistrasse 32, 4056 Basel, Switzerland \\ Correspondence to: Rüdiger Kilian (ruediger.kilian@unibas.ch)
}

Received: 30 April 2017 - Discussion started: 19 May 2017

Revised: 21 August 2017 - Accepted: 25 August 2017 - Published: 25 October 2017

\begin{abstract}
The crystallographic preferred orientations (textures) of three samples of Black Hills Quartzite (BHQ) deformed experimentally in the dislocation creep regimes 1,2 and 3 (according to Hirth and Tullis, 1992) have been analyzed using electron backscatter diffraction (EBSD). All samples were deformed to relatively high strain at temperatures of 850 to $915^{\circ} \mathrm{C}$ and are almost completely dynamically recrystallized. A texture transition from peripheral $[c]$ axes in regime 1 to a central $[c]$ maximum in regime 3 is observed. Separate pole figures are calculated for different grain sizes, aspect ratios and long-axis trends of grains, and high and low levels of intragranular deformation intensity as measured by the mean grain kernel average misorientation (gKAM). Misorientation relations are analyzed for grains of different texture components (named $\mathrm{Y}, \mathrm{B}, \mathrm{R}$ and $\sigma$ grains, with reference to previously published "prism", "basal", "rhomb" and " $\sigma_{1}$ " grains). Results show that regimes 1 and 3 correspond to clear end-member textures, with regime 2 being transitional. Texture strength and the development of a central $[c]$-axis maximum from a girdle distribution depend on deformation intensity at the grain scale and on the contribution of dislocation creep, which increases towards regime 3. Adding to this calculations of resolved shear stresses and misorientation analysis, it becomes clear that the peripheral $[c]$-axis maximum in regime 1 is not due to deformation by basal $\langle a\rangle$ slip. Instead, we interpret the texture transition as a result of different texture forming processes, one being more efficient at high stresses (nucleation or growth of grains with peripheral $[c]$ axes), the other depending on strain (dislocation glide involving prism and rhomb $\langle a\rangle$ slip systems), and not as a result of temperature-dependent activity of different slip systems.
\end{abstract}

\section{Introduction}

Quartz textures (crystallographic preferred orientation), usually presented in the form of pole figures, are frequently used for the analysis of deformed rocks. Optical, X-ray or electron backscatter diffraction (EBSD) data are widely considered to make interpretations about deformation kinematics such as shear senses (e.g., Berthe et al., 1979; Simpson, 1980; Kilian et al., 2011b), vorticity (e.g., Wallis, 1995; Xypolias, 2009) and progressive strain type (e.g., Price, 1985; Sullivan and Beane, 2010), deformation mechanisms (e.g., Behrmann and Mainprice, 1987; Song and Ree, 2007; Kilian et al., 2011a) or recrystallization processes (e.g., Knipe and Law, 1987; Stipp et al., 2002), the involved slip systems (e.g., Bouchez and Pecher, 1981; Schmid and Casey, 1986; Law et al., 1990), or even to estimate synkinematic temperatures (e.g., Kruhl, 1996; Morgan and Law, 2004; Thigpen et al., 2010). However, in most cases, the underlying mechanisms and processes are poorly understood. For example, the exact nature of the relationship between temperature and recrystallization mechanisms (Stipp et al., 2002), or between the geometry of the pole figure skeleton and strain in polycrystalline materials, is not entirely resolved (e.g., Schmid and Casey, 1986; Wenk and Christie, 1991). Transitions in texture types have been correlated with changes in recrystallization mechanisms or were explained by a temperature dependence of the slip systems involved in crystal plastic deformation (e.g., Tullis et al., 1973). There have been speculations on a temperature dependence of slip systems, either caused by a temperature-dependent critical resolved shear stress during glide (Hobbs, 1985) or anisotropic diffusion during climb (Blacic, 1975). However, conclusions have only been found for a transition from $\langle a\rangle$ to $\langle\mathrm{c}\rangle$ Burgers vectors towards very high temperatures (e.g., Mainprice et al., 1986). For $\langle a\rangle$ slip, 
a temperature-dependent activation of different slip systems has not been convincingly demonstrated. Conversely, a dependence of texture on bulk strain was recognized in experiments and nature (e.g., Heilbronner and Tullis, 2006; Pennacchioni et al., 2010), which is incompatible with a purely temperature-controlled development of specific texture type.

In experimentally deformed quartzites, regimes of different mechanical behavior and distinct microstructures have been recognized as three distinct dislocation creep regimes (Hirth and Tullis, 1992). Regime 1 is characterized by a high yield strength and substantial strain softening and nonrecrystallized grains deforming by fracturing and dislocation glide and climb (Hirth and Tullis, 1992; Stipp and Kunze, 2008). In these samples recrystallization occurs by bulging or nucleation and growth of new grains. Aggregates of newly formed grains are thought to deform by a dislocation process with a substantial contribution of grain boundary sliding (Tullis, 2002; Stipp and Kunze, 2008). Regime 2 samples yield at lower stresses and no pronounced weakening is observed. Incipient subgrain rotation recrystallization (SGR) has been inferred (DellAngelo and Tullis, 1989). Regime 3 exhibits the lowest flow stresses, SGR is predominant and some workers observe synkinematic normal grain growth (Gleason et al., 1993; Stipp et al., 2006) or abnormal grain growth (Heilbronner and Tullis, 2006), potentially in relation to texture development.

In this contribution we will focus on the following questions: which factors influence the texture geometry (shape of pole figure skeletons)? Is the texture controlled by deformation temperature, geometry and kinematics, or recrystallization processes? How reliably can certain texture components be used to infer the activity of a specific slip system? To this end, EBSD data obtained from Black Hills Quartzite (BHQ; original samples of Heilbronner and Tullis, 2002, 2006) experimentally deformed in the three dislocation creep regimes (Hirth and Tullis, 1992) were examined.

\section{Methods}

\subsection{Experiments and samples}

The samples analyzed are experimentally deformed BHQ of Heilbronner and Tullis (2002, 2006). Slabs of BHQ 1 to $1.5 \mathrm{~mm}$ thick were deformed in a modified Griggs-type deformation apparatus. The slabs were placed between two $45^{\circ}$ pre-cut forcing blocks of single crystal Brazil quartz (Fig. 1a). Experiments were performed "as is" or with $0.17 \mathrm{wt} \% \mathrm{H}_{2} \mathrm{O}$ added $\left(\sim 11000 \mathrm{ppmH} / 10^{6} \mathrm{Si}\right)$ in mechanically sealed Pt jackets. For experimental conditions and bulk strain, see Table 1. All samples are deformed to about the same bulk strain and for regime 3, a lower strain sample is additionally examined. Details of the experimental procedures are provided in Heilbronner and Tullis $(2002,2006)$ and in the companion paper (Heilbronner and Kilian, 2017). Sam- (a)

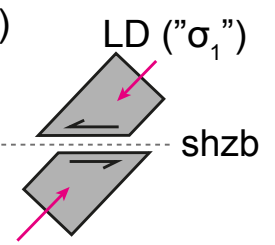

(c)

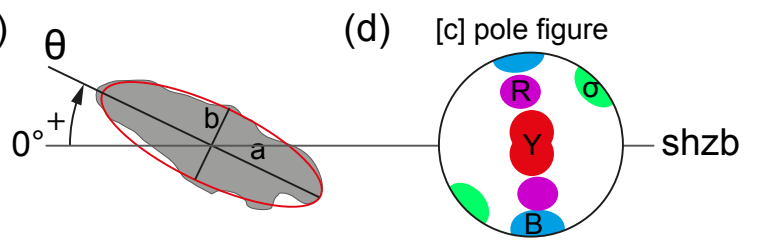

Figure 1. Definitions and reference frames. (a) Schematic section through general shear assembly: sample is located between quartz forcing blocks; loading direction (LD) at $45^{\circ}$ with respect to the shear zone boundary (shzb). (b) Strain reference framework: longaxis direction of the strain ellipsoid $\left(\theta^{\prime}\right)$, instantaneous stretching directions (ISA $\left.{ }_{1}, \mathrm{ISA}_{2}\right)$ and trace of the plane with the maximum shear stress $\left(\mathrm{ISA}_{2}+45^{\circ}\right.$ ). (c) Grain-scale reference frame for best-fit ellipses with grain long-axis direction $(\theta)$ and aspect ratio $(R=a / b)$. (d) Pole figure with shear zone boundary horizontal and schematic positions of $[c]$-axis directions corresponding to $\mathrm{Y}, \mathrm{B}, \mathrm{R}$ and $\sigma$ domains. Angles are counted clockwise, with 0 in the "west". Pole figure is an equal area, upper hemisphere projection.

ple strain and directions (Fig. 1b) such as the principal strain axes and the instantaneous stretching axes (ISA) were calculated from final displacement of forcing blocks and initial and final sample thickness under the assumption of steady general shear, according to Fossen and Tikoff (1993). Note that $\gamma_{\text {true }}$ values (Table 1) are not the same as and usually smaller than the $\gamma$ values typically listed in the experimental literature, including Heilbronner and Tullis $(2002,2006)$.

\subsection{EBSD data processing and analysis}

EBSD maps were collected on a Zeiss Merlin field emission gun scanning electron microscope, equipped with an Oxford EBSD camera in low vacuum mode, using $2 \times 2$ or $4 \times 4$ binning, $20 \mathrm{kV}$ acceleration voltage, a probe current of 6-9 nA, and step sizes of 0.5 and $1 \mu \mathrm{m}$. Unless otherwise specified, only the maps of the high-bulk-strain experiments w1092, w946 and w935 were analyzed (details in Heilbronner and Kilian, 2017). For data cleanup and processing, the MTEX toolbox by Ralf Hielscher was used (https://mtex-toolbox.github.io/; e.g., Bachmann et al., 2011; Mainprice et al., 2015). Single mis-indexed pixels were deleted and reconstructed together with single nonindexed pixels. Non-indexed areas less than two pixels wide were filled during noise removal using a half-quadratic filter (Bergmann et al., 2016). The procedure was adjusted to be edge-preserving for continuous boundaries above a $1.3^{\circ}$ misorientation angle. Grains were calculated with a threshold of a $10^{\circ}$ boundary misorientation angle using the point group 
Table 1. Experimental conditions and sample strain.

\begin{tabular}{lrrrrrrrrrrr}
\hline $\begin{array}{l}\text { Experiment } \\
\text { (regime) }\end{array}$ & $\begin{array}{r}T \\
\left({ }^{\circ} \mathrm{C}\right)\end{array}$ & $\begin{array}{r}P \\
(\mathrm{GPa})\end{array}$ & $\begin{array}{r}\dot{\gamma}_{\mathrm{max}} \\
\left(10^{-5} \mathrm{~s}^{-1}\right)\end{array}$ & $\begin{array}{r}\mathrm{H}_{2} \mathrm{O} \\
(\mathrm{wt} \%)\end{array}$ & $\begin{array}{r}\tau_{\text {peak }} \\
(\mathrm{MPa})\end{array}$ & $\begin{array}{r}\tau_{\text {flow }} \\
(\mathrm{MPa})\end{array}$ & $\begin{array}{r}\mathrm{th}_{0} \\
(\mathrm{~mm})\end{array}$ & $\begin{array}{r}\mathrm{th}_{\mathrm{f}} \\
(\mathrm{mm})\end{array}$ & $\begin{array}{r}45^{\circ} \text { disp. } \\
(\mathrm{mm})\end{array}$ & $\gamma_{\text {true }}$ & $R_{\mathrm{f}}$ \\
\hline $\mathrm{w} 1092(1)$ & 850 & 1.55 & 2.4 & - & 647 & 314 & 1.45 & 0.88 & 5.05 & 3.3 & 15.0 \\
\hline w946(2) & 875 & 1.5 & 3.1 & 0.17 & 220 & 201 & 1.24 & 0.65 & 4.44 & 3.3 & 16.5 \\
\hline w935 (3) & 915 & 1.5 & 2.8 & 0.17 & - & 103 & 1.27 & 0.69 & 3.87 & 2.9 & 12.9 \\
w1010 (3) & 915 & 1.55 & 2.1 & 0.17 & - & 105 & 1.27 & 1.03 & 2.65 & 2.1 & 6.5 \\
\hline
\end{tabular}

Shear stresses $\left(\tau_{\text {peak }}, \tau_{\text {flow }}\right)$ and strain rates $\left(\dot{\gamma}_{\text {max }}\right)$ are derived in Heilbronner and Kilian (2017). tho and the are sample thicknesses before and after the experiments; " $45^{\circ}$ disp." is the displacement parallel to the forcing blocks; $\gamma_{\text {true }}$ is the matrix shear strain; $R_{\mathrm{f}}$ is the strain ratio $\left(\sqrt{\lambda_{1}} / \sqrt{\lambda_{3}}\right)$.

622 and transforming the grain mean orientation back into trigonal point group 321. This procedure avoids Dauphiné twin boundaries $\left(60^{\circ}\right.$ rotation around $\left.[c]\right)$ being erroneously identified as grain boundaries, and the mean orientation of the "hexagonal" grain is equivalent to the modal orientation of the "trigonal" grain. The segmentation procedure yields identical results as a segmentation with trigonal symmetry and merging grains with boundaries, obeying the Dauphiné twin relationship. The grain size is given by the diameter of an area-equivalent circle. The grain long axis and aspect ratio are obtained from an area-equivalent best-fit ellipse.

Crystal directions [0001] and $\langle 11 \overline{2} 0\rangle$ are abbreviated as [c] and $\langle a\rangle$, and poles to planes $(0001),\{10 \overline{1} 0\},\{10 \overline{1} 1\},\{01 \overline{1} 1\}$, $\{10 \overline{1} 2\}$ and $\{01 \overline{1} 2\}$ are abbreviated as $(c),\{m\},\{r\},\{z\},\{\pi\}$ and $\left\{\pi^{\prime}\right\}$. Other crystal directions will be given with numerical values as \{planes\} or $\langle$ axes $\rangle$.

Contoured pole figures and inverse pole figures (IPFs) are calculated from the orientation distribution functions (ODFs). The ODF was calculated either from all measurements (area weighted) or from the grain modal orientations (one orientation per grain). In the case of ODF calculations, a de la Vallée-Poussin kernel was used. The kernel width was either fixed or estimated using the Kullback-Leibler crossvalidation implementation in MTEX. Estimated kernel half widths are between 7 and $14^{\circ}$. Texture strength is given as texture index (J-index, L2-norm of the ODF), pole figure index (pfJ; Mainprice et al., 2015) and maximum of pole figure densities. When comparing pfJ values of different crystal directions, the respective multiplicity $([c]: 2,\langle a\rangle: 3,\{m, r, z\}: 6)$ has to be taken into account.

Specific types of textures and certain texture components have been given genetic or descriptive terms in the literature. In particular, grains with a specific $[c]$-axis direction have been interpreted to be suitably oriented for the activity of specific slip systems with the $\langle a\rangle$ direction as a Burgers vector and have therefore been called basal, prism or rhomb grains (Bouchez and Pecher, 1981; Heilbronner and Tullis, 2006). Here we will adapt a naming scheme of $Y, B, R$ and $\sigma$ grains or domains based on the $[c]$-axis direction shown in Fig. 1d. However, we do not implicitly assume that $\mathrm{R}$ grains have to deform by rhomb- $\langle a\rangle$ slip. All azimuthal angles will have the origin in the "west", increasing clockwise, inclination being $0^{\circ}$ in the center of the pole figure. Directions in the first and third quadrants (NW and SE) are inclined with a sinistral sense of shear.

\subsection{1 gKAM}

The grain kernel average misorientation (gKAM) is calculated from the kernel average misorientation (KAM) from noise-reduced EBSD data (Fig. 2). The KAM is the average misorientation angle over a kernel computed for each measurement point. Misorientation angles above a threshold of $8^{\circ}$ were ignored. The gKAM is the sum of the KAM within a grain divided by the number of measurements with the grain. The size of the kernel was individually chosen to be of the order of 24 or 40 pixels, thereby suppressing any grain size dependency. The gKAM is a measure of misorientation density and depends on the misorientation angle and the number of low-angle boundaries within a grain. In noise-free data, the magnitude of the gKAM can therefore be considered as an indirect measure of intragranular deformation intensity, i.e., of how much a grain has been deformed during dislocation creep. An advantage over the grain orientation spread (GOS) is that it will not be influenced by interior high-angle boundaries or twins; however, the gKAM does not measure continuous lattice bending.

\section{Results}

\subsection{Pole figure geometry}

In regime 1, the pole figures show a broad, asymmetric peripheral distribution of $[c]$ axes with a maximum at $\sim 78^{\circ}$ (inclined with the sense of shear; Fig. 3a). Minor densities occur at $\sim 130^{\circ}$ roughly parallel to the shortening axis in the experiment and a tail towards the center of the pole figure. $\langle a\rangle$ shows a major maximum at the periphery, forming an angle of $\sim-12^{\circ}$ with the shear plane. Two minor maxima of $\langle a\rangle$ lie on great circles inclined $\sim 15^{\circ}$ with respect to the pole figure center. Poles to $\{r\}$ show a symmetric peripheral maximum inclined against the sense of shear at $\sim 120^{\circ}$ and a 

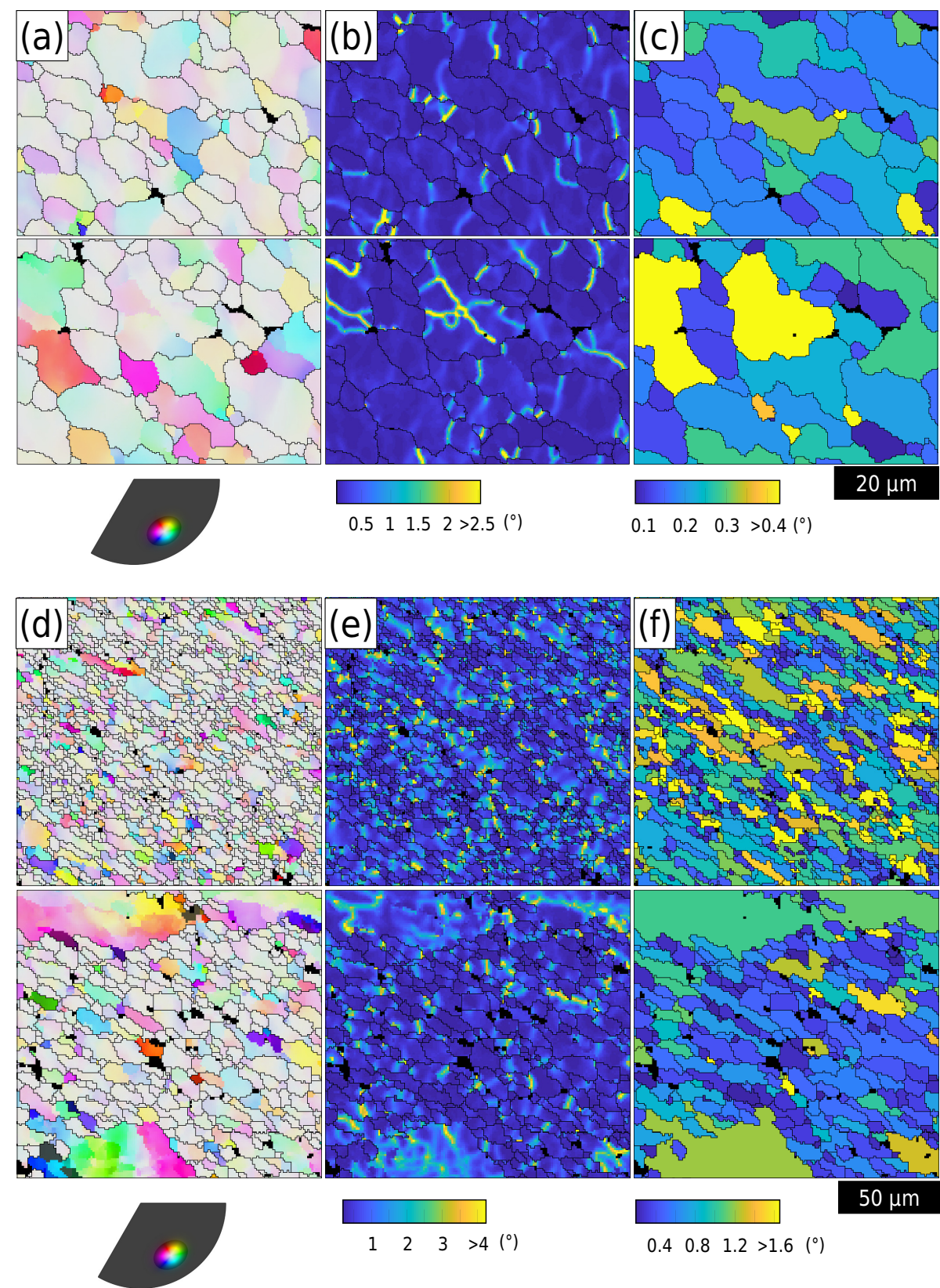

Figure 2. Explanation of the mean grain kernel average misorientation (gKAM): crops of EBSD maps of 0.25 and $1 \mu \mathrm{m}$ step size showing (a, d) the misorientation to the mean orientation after noise removal. Color lookup table shows misorientations with a misorientation angle of up to $15^{\circ}$. (b, e) Kernel average misorientation (KAM) of a 24-pixel neighborhood. (c, f) gKAM as defined by the sum of the KAMs of all pixels within a grain divided by the number of pixels.

girdle distribution perpendicular to the peripheral maximum. In regime 3 (high strain), $[c]$-axis pole figures show an elongated maximum in the center of the pole figure, overlying a weak, kinked single girdle. Internally the maximum is composed of two maxima at an angular distance of about $10-20^{\circ}$, symmetrically arranged above and below the shear plane (see Heilbronner and Kilian, 2017). $\langle a\rangle$ axes form a major maximum at $\sim-10^{\circ}$. In pole figures of regime $2,[c]$ axes are distributed along a kinked single girdle, presenting a combi- nation of regimes 1 and 3 pole figures. $\langle a\rangle$ axes form a strong maximum at $\sim-10^{\circ}$ and the $\{r\}$ pole figure resembles the one observed in regime 1 . The pole figures of the low-strain regime 3 sample share many features with those of regime 1 , particularly with respect to the peripheral $[c]$ axes. While the overall texture is weak, $\{r\}$ displays a stronger alignment relative to $[c]$ when compared with the high-strain samples of regimes 1 and 2 . 


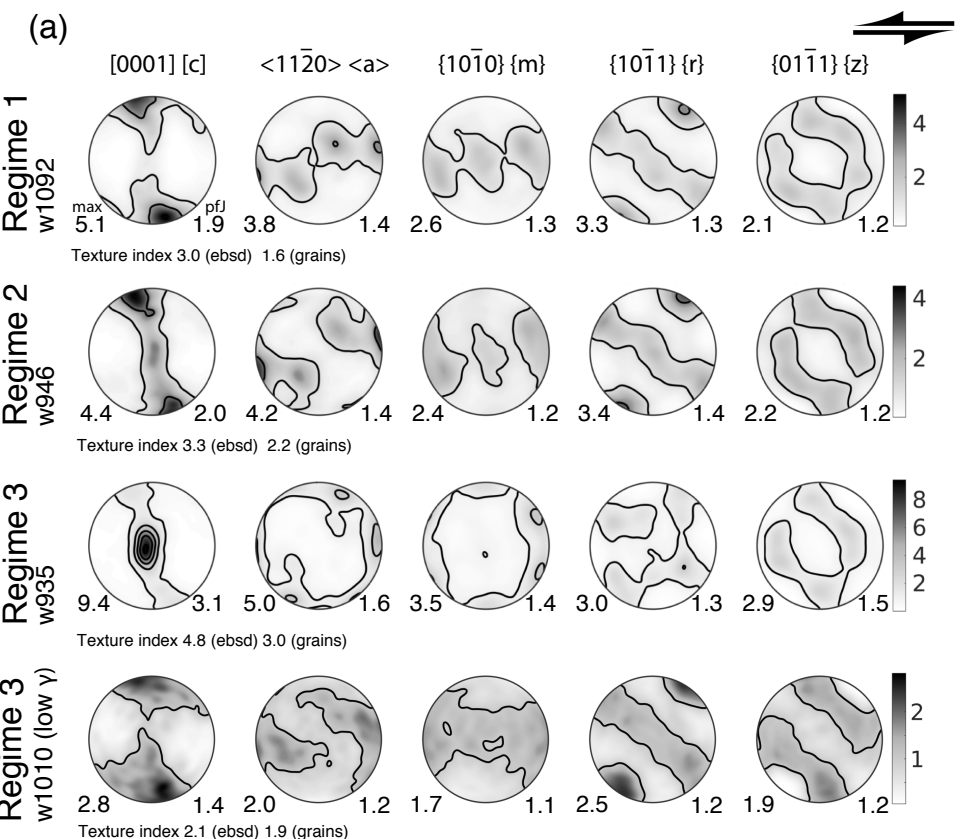

(b)
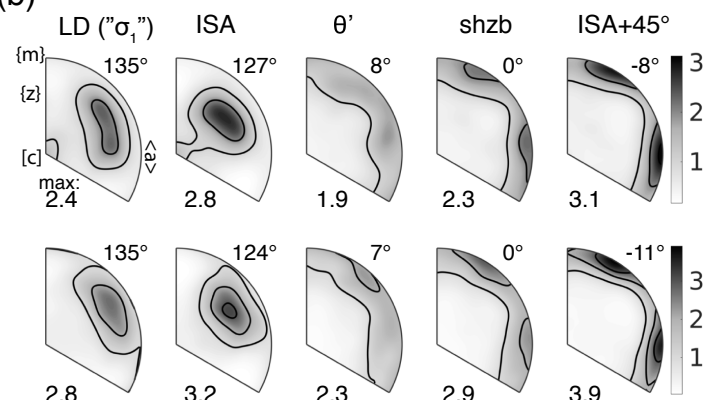

2.9
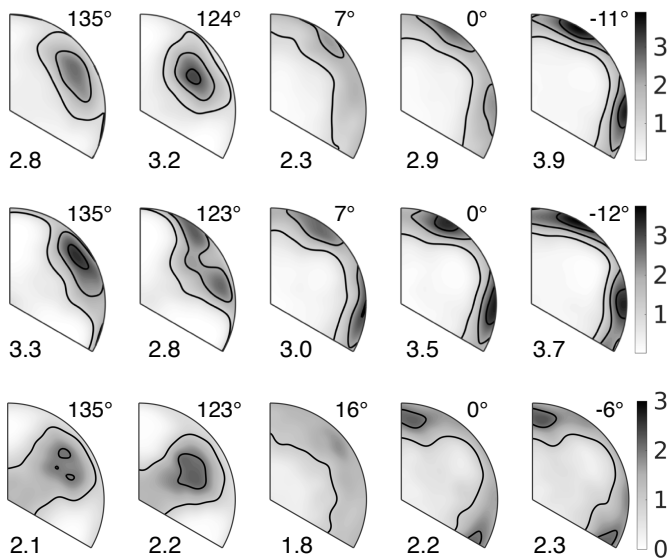

Figure 3. (a) Pole figures for $[c],\langle a\rangle,\{m\},\{r\}$ and $\{z\}$ from EBSD maps with one orientation per pixel of recrystallized grains. Maximum density and pfJ, shown at the left and right of each pole figure. Texture index given for one orientation per pixel and one orientation per grain. Kernel half width is $6^{\circ}$; contour intervals are at 2 times uniform density. (b) Inverse pole figures for selected reference directions (see Fig. 1), with a trend indicated above each plot. Contour intervals at 1 times uniform density.

On inverse pole figures of sample strain and other reference directions (Fig. 3b), the strongest alignment, in all regimes, is found for $\langle a\rangle$ and the $\mathrm{ISA}_{2}+45^{\circ}$ at $\sim-10^{\circ}$, at the trace of the plane with the highest shear stress. In IPFs with a reference direction at $135^{\circ}$ (parallel to the direction of the load piston), all samples show a high density very close to $\{20 \overline{2} 1\}$. Using the ISA $2\left(\sim 10^{\circ}\right.$ steeper than the direction related to the load piston) as a reference direction, in regimes 1 and 2 a very strong alignment of $\{r\}$ is found. The lowstrain sample of regime 3 again shares many similarities with regime 1, only the $\langle a\rangle$ alignment is missing.

\subsection{Orientation maps}

Orientation maps are color-coded for crystal directions parallel to specific reference directions (Fig. 4). Using the structural $Y$ direction as the reference direction, an increasing number of orientations with $[c]$ parallel to $\mathrm{Y}$ (Y domains) from regime 1 to regime 3 are clearly recognized, corresponding to an increasing number of red pixels (Fig. 4a). In regime 2, Y domains appear in areas mostly devoid of larger porphyroclasts and with a smaller grain size. In regime 3, $\mathrm{Y}$ grains form bands defining a foliation.

Figure $4 \mathrm{~b}$ shows an IPF color-coding using the trend of the plane with the highest inferred shear stress, i.e., $45^{\circ}$ from the $\mathrm{ISA}_{2}$ as a reference direction. To omit any distinction between $\langle a\rangle$ and $\langle-a\rangle$ while preventing color jumps, a colorcoding for an increased crystal symmetry was used. Maps show a relatively homogeneous distribution of $\langle \pm a\rangle$ parallel to the reference direction across all three samples. Notably in regimes 1 and 2 samples, grains inside bands with a shear band geometry show an alignment of $[c]$ close to the shear plane (green pixels), rather than at a high angle.

\subsection{Variation in pole figure geometry within classes of grain size, aspect ratio and long-axis direction}

Pole figures are calculated for grains grouped with respect to aspect ratio $(R)$ and grain size $(d)$, and aspect ratio and longaxis trend $(\theta ;$ Fig. 5). Grains from different maps with identical step size for low- and high-total-strain experiments of each regime have been combined to obtain sufficiently large datasets. Class boundaries for individual properties are chosen such that classes are equally populated. Combinations of two properties are shown in $3 \times 4$ matrices. As the distributions of the grain properties are generally skewed, classes defined by two properties cannot be equally populated. Kernel parameters for the texture calculations were estimated individually for each class and because of that, pole figure geometries are comparable and densities of pole figures of poorly populated classes will not be overestimated.

For all regimes, $[c]$ pole figures show higher densities towards a higher aspect ratio and towards larger grain sizes (Fig. 5a, b). In regime 1, small grains show the broadest distribution, dispersed along the periphery. With increasing aspect ratio, a weak single girdle is recognized. In regime 3 , 
(a)

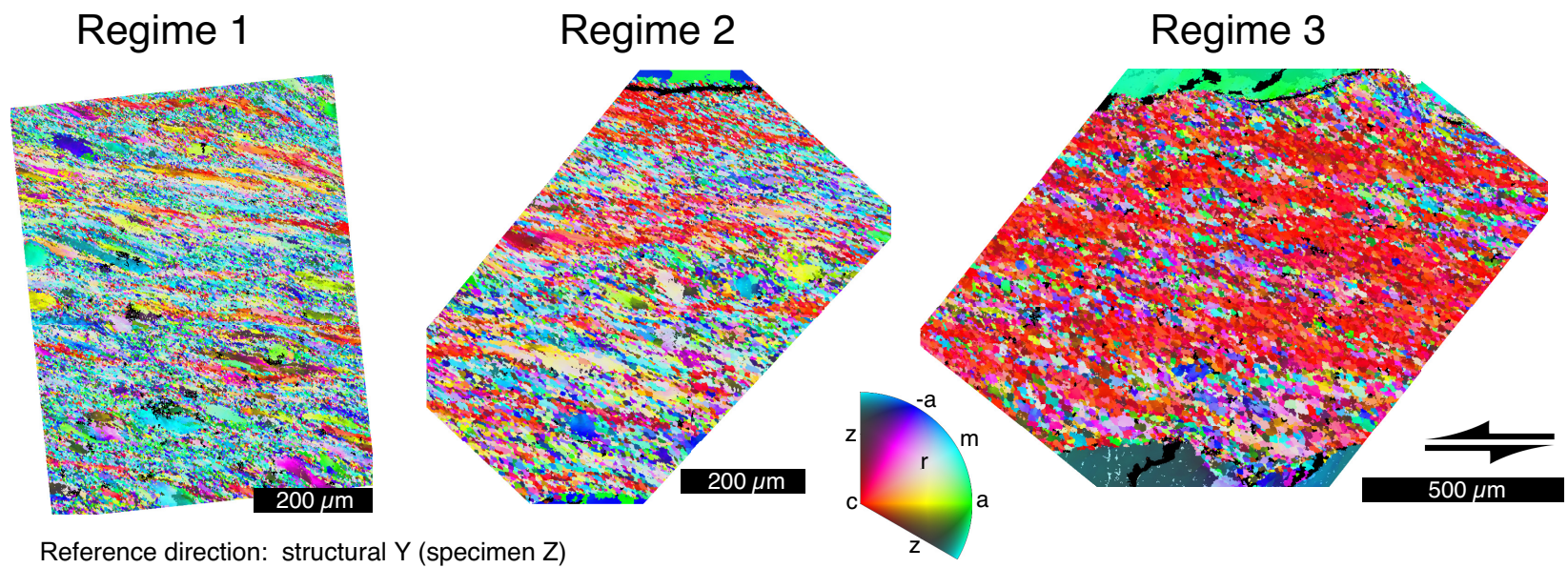

(b)

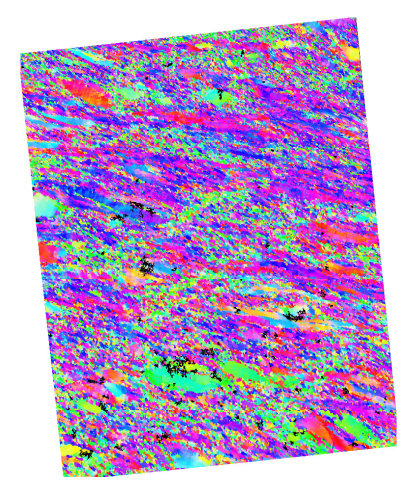

Reference direction: $-8^{\circ}$ $\left(\mathrm{ISA}+45^{\circ}\right)$

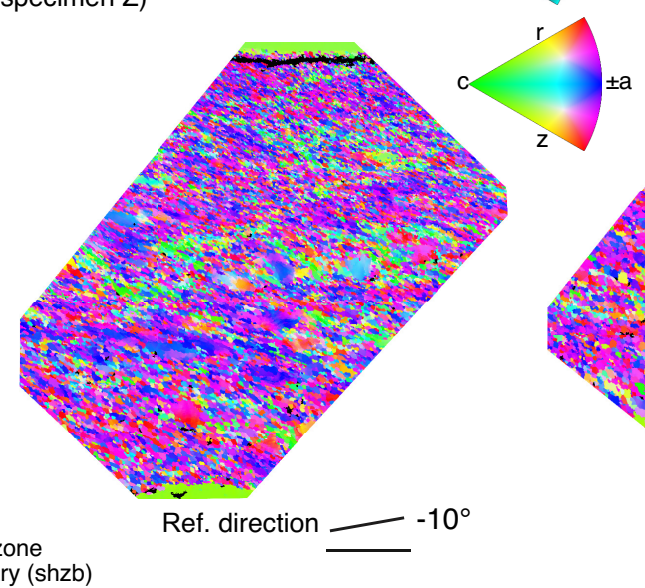

Regime 3

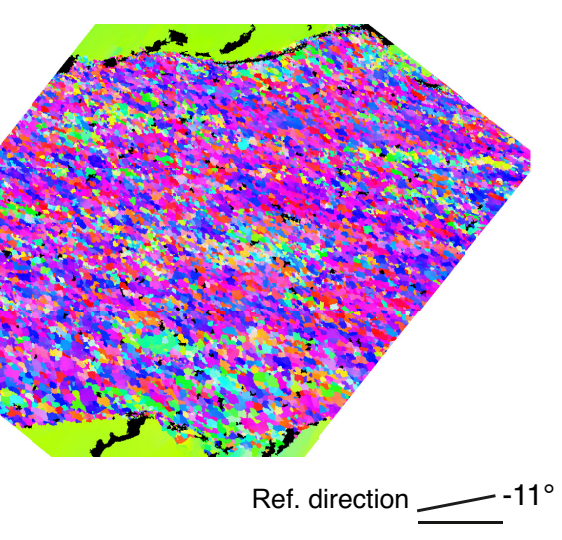

Figure 4. Orientation maps for samples w1092, w946 and w935. (a) Inverse pole figure color-coding using the inferred vorticity axis (equal for specimen $Z$ and the strain or structural $Y$ direction) as a reference direction. Color key for purely rotational point group. (b) Inverse pole figure color-coding using the $\mathrm{ISA}_{2}+45^{\circ}$ as a reference direction (direction of maximum shear stress) and a color key for hexagonal Laue symmetry. Maps of regimes 2 and 3 show quartz forcing blocks at the top and bottom.

$[c]$ pole figures for large grains with high aspect ratios show the highest densities at the elongated central maximum and lower peripheral maxima and minor off-periphery maxima, forming a single kinked girdle. In pole figures for regime 2, the same relationship is observed. A single kinked girdle develops with peripheral and central maxima, which can be described as a mixture between regime 1 and regime 2 pole figures.

For $[c]$-axis pole figures of grains grouped with respect to $R$ and $\theta$, the highest degree of alignment is observed in classes with the largest $R$ and $\theta$ being approximately parallel to the ISA $A_{1}$. In regime 1 , the second-strongest $[c]$-axis alignments are found in the $\theta$ class containing the trend of the shear plane and, in regimes 2 and 3 , in the $\theta$ class with steeper long-axis trends. The weakest $[c]$-axis alignment can be found in classes that contain grains with $\theta$ pointing against the sense of shear. While the positions of maxima along the girdle vary from regime 1 to 2 to 3 , and additionally within each regime, the classes with the highest aspect ratios and the strongest alignment of $\theta$ show an increasing concentration of $[c]$ in the central regions of the girdle.

The position of the peripheral part of the kinked $[c]$-axis girdles shows a consistent variation of up to $15^{\circ}$ with $\theta$, being most inclined (with the sense of shear) in classes containing the trend of the shear plane and being steepest in the classes in which $\theta$ is steeper than the maximum. This variation is most clearly expressed for high aspect ratios. In a few cases, a secondary, peripheral $[c]$-axis maximum (or relict cross girdle) defines an opening angle that varies between 50 to about $80^{\circ}$.

\subsection{Pole figures of grain properties}

Pole figures of average grain properties are obtained by calculating spherical interpolations for grain size, aspect ratio and axial ratio (the inverse of the aspect ratio), based on the [c]-axis direction of grains smaller than $25 \mu \mathrm{m}$ (Fig. 6). For details on the procedure, see Appendix A1. 


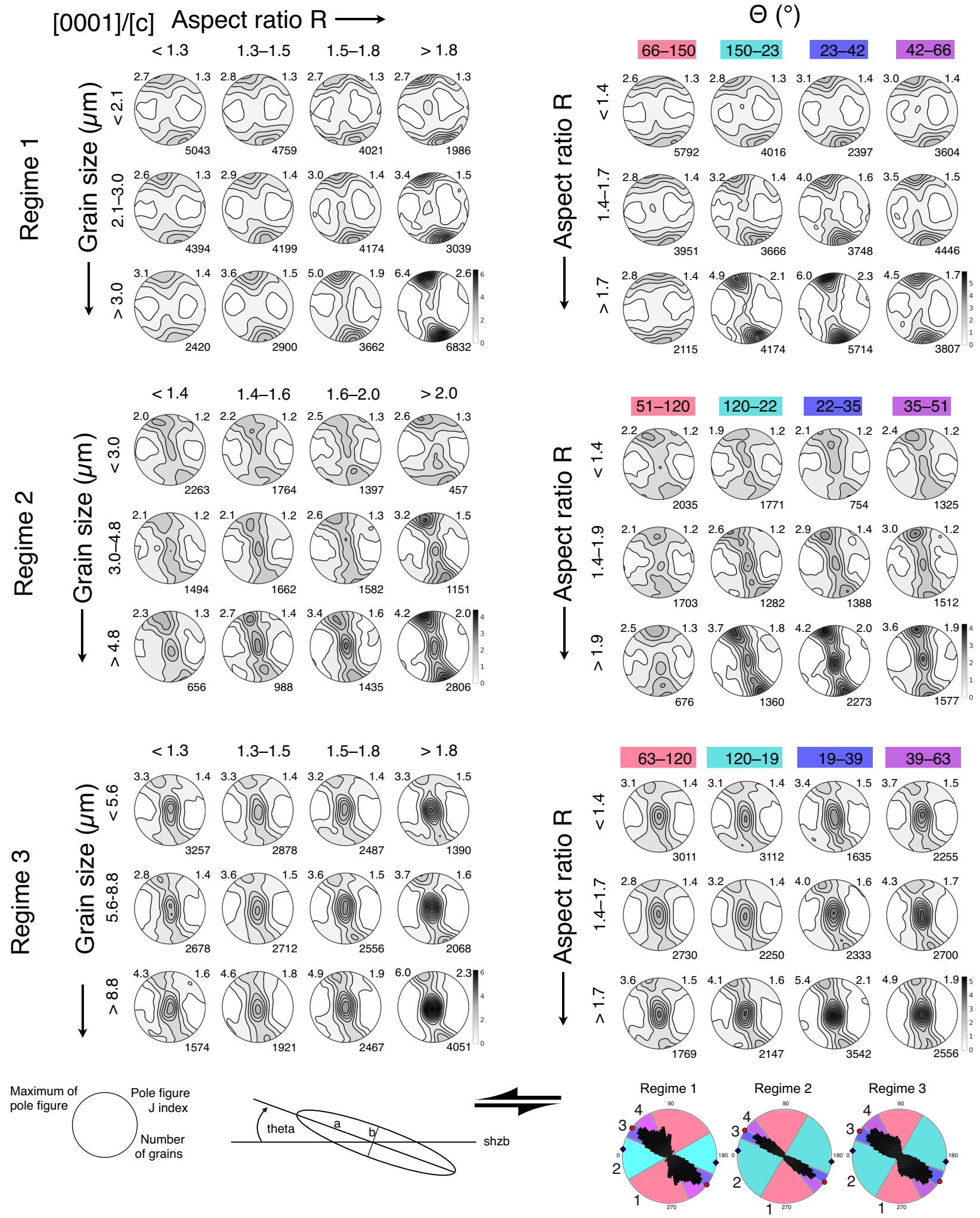

Figure 5. $C$-axis pole figures for different classes of aspect ratio $R$ and grain size in (a) and grain long-axis trend $\theta$ and $R$ in (b). Class limits for each property are at equally spaced quantiles of the entire population. Textures are calculated for one orientation per grain (grain modal orientation). Contours at 0.5 times uniform density. Rose diagrams at the lower right show the $\theta$ distribution and the corresponding classes. Blue diamonds indicate the direction of $\theta^{\prime}$ (strain ellipsoid long axis), and the red circle indicates the direction of the ISA . 


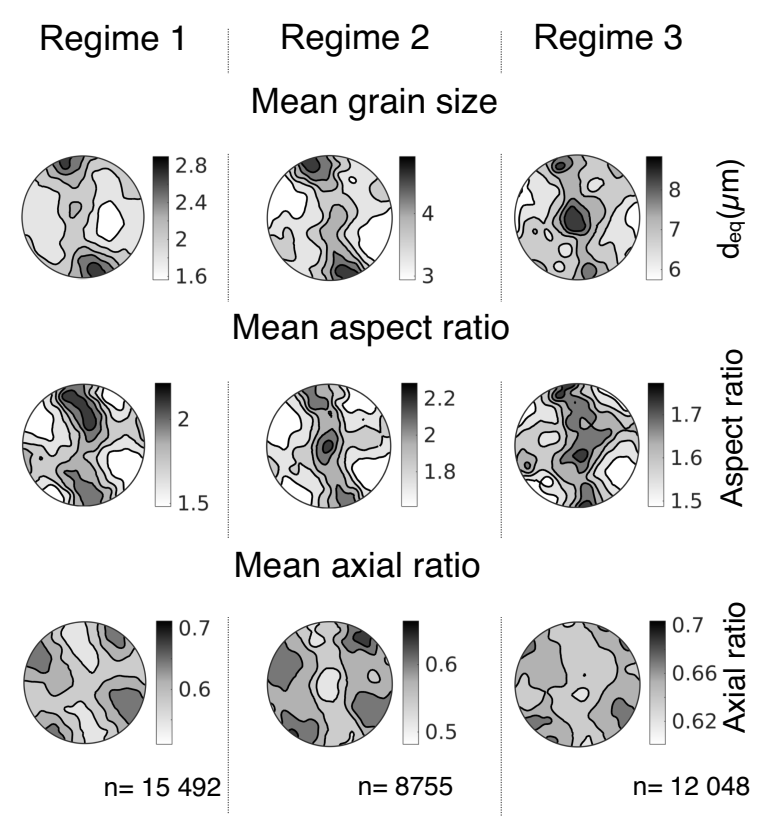

Figure 6. Pole figures showing average grain size $(d)$, aspect ratio $(R)$ and axial ratio $(1 / R)$ as a function of $[c]$-axis directions. The projection is upper hemisphere, equal area, and the grayscale indicates number-weighted averages of $d, R$ and $1 / R$. Both $R$ and $1 / R$ are displayed to separately visualize elongated and isometric grains.

For regimes 1 and 2 the average grain size is largest at the periphery and for regime 3 it is in the center of the $[c]$-axis pole figure space. High average aspect ratios are found along a kinked girdle for regimes 1 and 2 and on a weak cross girdle for regime 3. In regimes 2 and 3, the largest average aspect ratios along these girdles are located at the center of the girdle. In contrast, the largest average axial ratios are found in two peripheral directions, at $\sim 30-35$ and $\sim 125^{\circ}$.

\subsection{Pole figures for high and low gKAMs}

Pole figures are calculated for all orientations of grains with a gKAM below and above the median gKAM and below the 20 and above the $80 \%$ quantile values (Fig. 7a). For regimes 1 and 2 , grains $<12 \mu \mathrm{m}$ and for regime 3 grains $<25 \mu \mathrm{m}$ are considered. $[c]$-axis pole figures for a high gKAM show a strong degree of ordering and a tendency toward higher pole densities along the kinked single girdle away from the periphery. From regime 2, peripheral maxima shift to Y maxima and secondary peripheral maxima disappear in the highgKAM classes. Figure $7 \mathrm{~b}$ shows grains color-coded for a gKAM larger or smaller than the median gKAM value, visualizing the strain gradient inside the samples.

\subsection{Quantitative comparison of texture strength}

Assuming that texture strength, i.e., texture index, is an expression of the contribution of texture-forming processes to deformation, a quantitative comparison of texture strength as a function of gKAM, $R, d$ and $\theta$ is performed (Fig. 8). See Appendix A2 for details on the method.

In all regimes, the texture index increases with increasing aspect ratio and for higher aspect ratios also for increasing grain size. Also, the classes containing the largest (recrystallized) grains and highest aspect ratio possess the highest texture strength (Fig. 8a). In Fig. 8b it is observed that the texture index continuously increases towards higher aspect ratios. In regime 1, the highest texture index is found for highgKAM classes at a $\theta$ of $\sim 20-30^{\circ}$. In regime 2 , the range of the texture index is smaller but the highest values are found for $\theta$ between the shear plane and up to $40^{\circ}$. In regime 3 , the highest texture index of $30-45^{\circ}$ is found in the $\theta$ class. In each regime and class, there is a general increase of the texture index from populations of grains with a low gKAM to those with a high gKAM.

The volume of the B fiber is largest for regime 1 and smallest in regime 3, while the volume of the Y fiber is smallest in regime 1 and largest in regime 2, reflecting what can be seen in the pole figures (Fig. 5). In both Fig. 8a and b, the trend in B-fiber volumes in regime 1, of Y-fiber volumes in regime 3 and corresponding texture indices is similar, showing an increase from low gKAM to high gKAM. Regime 2 does not show a large variation in B- and Y-fiber volumes as [c]-axis girdles host both components; only a small decrease in B-fiber and an increase in Y-fiber volume from low gKAM to high gKAM can be observed.

\subsection{Analysis of misorientation axes}

Misorientation axes have been determined in specimen and crystal coordinates for misorientation angles of $2-9^{\circ}$ for subsets of grains (Figs. 9, 10). The upper limit of $9^{\circ}$ is chosen to analyze only boundaries that have a high probability of being subgrain boundaries, the transition has been suggested to occur in the range of $9-14^{\circ}$ (Shigematsu et al., 2006). Subsets are chosen to contain grains with a modal orientation of up to $25^{\circ}$ with respect to the orientation modes of $\mathrm{Y}, \mathrm{B}, \mathrm{R}$ and $\sigma$ grains (Fig. 9a). To highlight the unique relation between misorientation axes in crystal and specimen coordinates, individual misorientation axes are color-coded such that misorientation axes in the specimen reference frame correspond to crystal directions. Misorientation axes in the crystal reference frame are colorized by the inclination of the axis in specimen coordinates (Fig. 10).

In all samples and for all types of grains, the axis distribution in specimen coordinates shows a maximum parallel to the structural $Y$ direction (Fig. 9b). In Y grains of all samples, misorientation axes are parallel to the $[c]$ axis. For B grains, densities of misorientation-axis distributions in crystal coordinates are very low; the highest densities are close to $\langle 10 \overline{1} 0\rangle$. Surprisingly, R grains show a maximum of misorientation axes around $[c]$ and only a slightly higher density close to $\langle 10 \overline{1} 2\rangle$ and $\langle 10 \overline{1} 1\rangle$. However, total densities also remain rather low. $\sigma$ grains, similar to $\mathrm{R}$ and $\mathrm{B}$ grains, have 

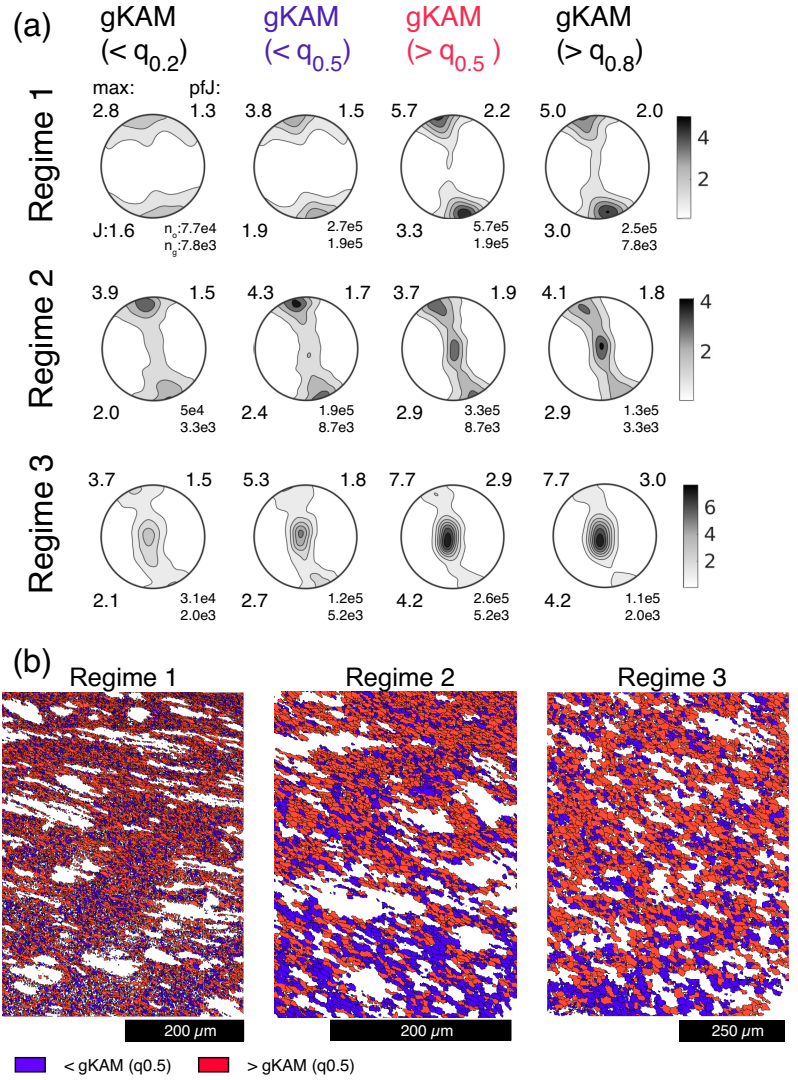

Figure 7. Dependencies of $[c]$-axis pole figures on gKAM: (a) $[c]-$ axis pole figures from all orientations of grains with a gKAM below the 0.2 quantile, below and above the median ( 0.5 quantile), and above the 0.8 quantile. For regimes 1 and 2 , only grains $\leq 12 \mu \mathrm{m}$, for regime 3 grains $\leq 25 \mu \mathrm{m}$, were used. In each pole figure, maximum density is given at top left, pfJ at top right, texture index at bottom left, and number of orientations $\left(n_{\mathrm{o}}\right)$ and corresponding number of grains $\left(n_{\mathrm{g}}\right)$ within class at the bottom right. Contours at 1 times the uniform. (b) Maps showing grains with a gKAM below (blue) and above (red) the median gKAM value.

misorientation-axis distributions that are rather weak and encounter the highest densities close to $\langle 10 \overline{1} 0\rangle$.

In specimen coordinates, the density distributions of misorientation axes of some $\mathrm{B}, \mathrm{R}$ and $\sigma$ grains form slightly elongated contours parallel to the trend of the corresponding $[c]$-axis direction. Also, it may seem paradoxical that $\mathrm{R}$ grains show the highest density of misorientation axes parallel to $[c]$ and at the same time parallel to the structural $Y$ direction while $\mathrm{R}$ grains have their $[c]$ axis $>30^{\circ}$ away from the $Y$ direction. In the color-coded plots (Fig. 10), the misorientation axes coinciding with the structural $Y$ direction correspond in B grains to crystal directions close to $\langle 10 \overline{10}\rangle$ and in $\mathrm{R}$ grains close to $\langle 10 \overline{1} 2\rangle,\langle 10 \overline{1} 1\rangle$ and $\sim\langle 7 \overline{25} 6\rangle$. Those directions coincide with the misorientation axes for kinematically ideal tilt boundaries related to $(c)\langle a\rangle$ slip in the case of $\mathrm{B}$ grains and $\{z\}\langle a\rangle$ to $\left\{p i^{\prime}\right\}\langle a\rangle$ and possibly the hypothet- ical $\{s\}\langle c-a\rangle$ slip in the case of $\mathrm{R}$ grains. For $\sigma$ grains, the total number of axes is too small to find a preferred crystal direction with a high statistical significance; most misorientation axes parallel to the $Y$ direction seem to coincide with $\langle 10 \overline{1} 0\rangle$ or $\langle 11 \overline{2} 0\rangle$. The elongation of the misorientation-axis distribution coincides with misorientation axes parallel to $[c]$ for the R grains and somewhere between the $\langle 10 \overline{1} 2\rangle,\langle 10 \overline{1} 1\rangle$ and $[c]$ directions for the $\mathrm{B}$ grains. These features are most prominent in the samples of regimes 2 and 3 . In specimen coordinates, this superposition causes the elliptical shape of the axis distribution. As a consequence, the most common misorientation axes interpreted from the density plot need not coincide with the kinematically ideal axis (parallel to the structural $Y$ direction) for tilt boundaries.

\subsection{Schmid factor analysis}

The generalized Schmid factor (Reid, 1973) is calculated for a given slip system and stress tensor and presents the ratio between the shear stress on the slip system and the norm of the macroscopic stress tensor. Since the general shear experiments are approximately plane strain and the displacement is resolved parallel to the boundary of the forcing block, we use a triaxial stress tensor. Schmid factors are calculated for all grain modal orientations, and their sum is divided by the number of orientations. For combinations of slip systems, Schmid factors are calculated for all slip systems in the combination and the maximum values are averaged.

The mean generalized Schmid factor is plotted as a function of the trend of the maximum principal stress direction of the stress tensor (Fig. 11). The highest Schmid factors are attained for $\sigma_{1}$ directions at about -10 to $-15^{\circ}$ from the loading direction. For single slip systems, in all regimes, $\left\{\pi^{\prime}\right\}\langle a\rangle$ or $\{z\}\langle a\rangle$ yield the highest Schmid factors. In regime 1 in which many grains have $[c]$-axis directions at the periphery of the pole figure, the highest mean Schmid factors are predicted for $\left\{\pi^{\prime}\right\}\langle a\rangle$. For combinations of slip systems, in regimes 2 and 3, $\{m\}\langle a\rangle+\left\{\pi^{\prime}\right\}\langle a\rangle+\{z\}\langle a\rangle$ always give the highest mean Schmid factors and are equally high in regime 1 as the combination of $\{m\}\langle a\rangle$ and $(c)\langle a\rangle$. The curve for $\{m\}\langle a\rangle$ shows a similar behavior as the curve for $\langle a\rangle$ slip on the positive rhombs, with a minimum mean Schmid factor at the position where most reasonable slip systems show a maximum. While this is logical for $\{r\}$ and $\{z\}$ for example, $\{m\}$ does not have this crystallographic dependency and this behavior is somewhat unexpected.

The $\sigma_{1}$ directions derived from these plots are in excellent agreement with $\sigma_{1}$ inferred from the ISA $A_{2}$ calculated from bulk sample geometry and $\sigma_{1}$ suggested by the positions of $\{r\}$ maxima in regimes 1 and 2 and low-strain regime 3 pole figures. We note that these three independent methods yield results that are a clear and significant deviation from the assumption that $\sigma_{1}$ is parallel to the loading axis in this type of experiment. We assume that this deviation of $\sim 10-15^{\circ}$ applies mainly to the deforming part of the sample. 

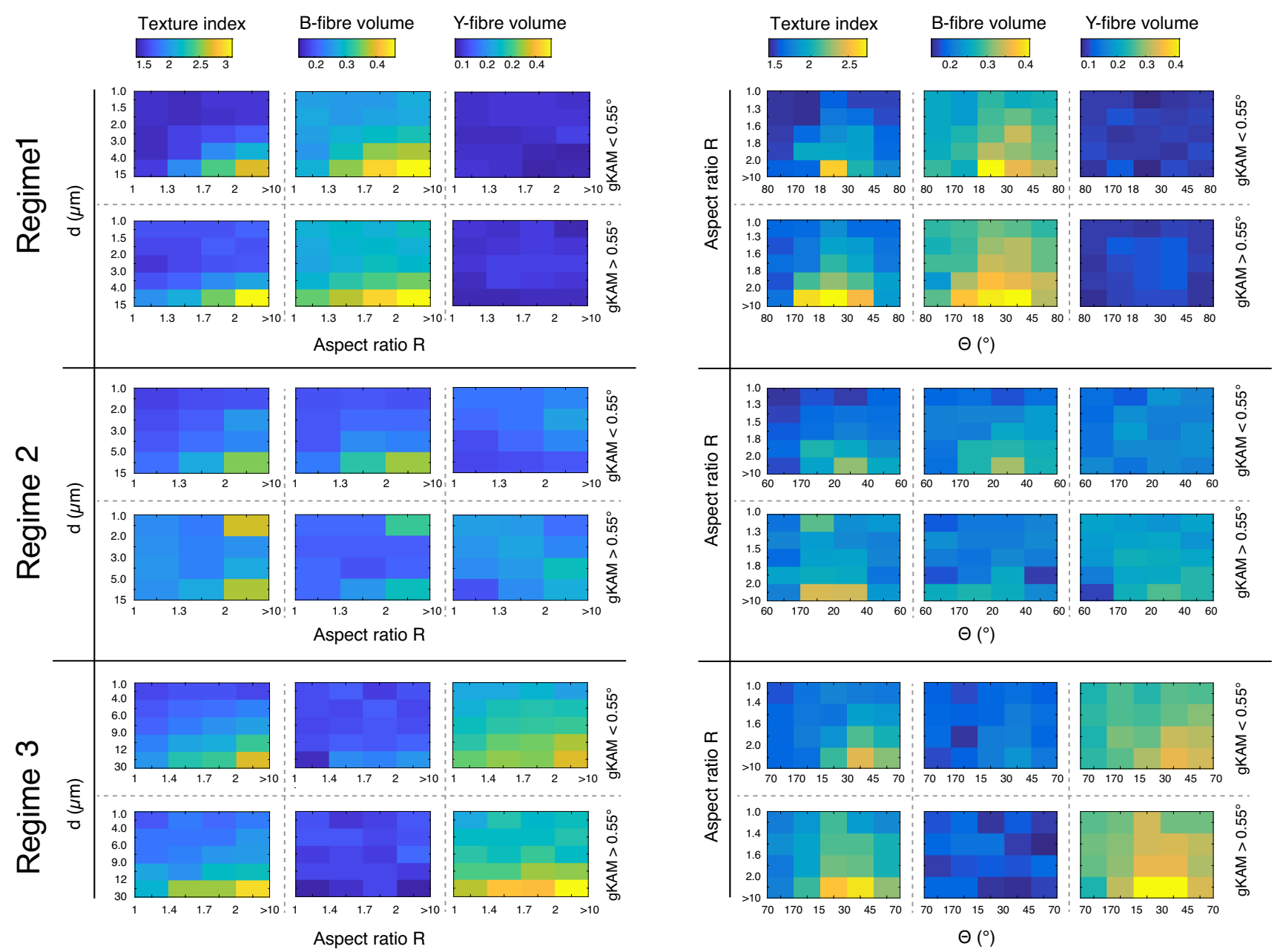

Figure 8. Quantitative comparison of texture index and volumes of texture components. Separate color maps for texture index, B-fiber and Y-fiber volume as a function of aspect ratio $R$, grain size $d$ and long-axis trend $\theta$, calculated for low- and high-gKAM populations. Fiber volumes are calculated as the volume of the ODF within a $30^{\circ}$ radius around a $[c]$-axis fiber directed towards the peripheral (B fiber) and the central $[c]$-axis maximum (Y fiber). Absolute values within each column of color maps are quantitatively comparable.

\section{Discussion}

Textures of the high-strain samples of all regimes share the alignment of $\langle a\rangle$ with the direction of maximum shear stress at $\sim-10^{\circ}$ from the shear plane. In regimes 1 and 2 as well as the lower-strain regime 3 , a strong alignment of the positive rhombohedral planes $\{r\}$ towards the ISA 2 is found. The most striking feature, however, is the transition of the geometry (skeleton) of the $[c]$-axis pole figure. $[c]$ is dispersed on the periphery at a high angle to the shear plane in regime 1 and at low strain in regime 3, distributed along a kinked single girdle in regime 2 , and forms the central maximum at the structural $Y$ direction in regime 3. This transition coincides with an increase in the texture strength in the highstrain samples from regime 1 to regime 3 . The same trend can be observed within individual samples as a function of grainscale deformation intensity. In the following, the origin of this texture transition will be discussed with regard to active deformation mechanisms and processes and its significance for the interpretation of quartz texture data as indicators of deformation conditions.

\subsection{Texture transitions in nature and experiments}

Pole figure skeletons similar to the ones shown here have also been reported form naturally deformed rocks (e.g., Bouchez and Pecher, 1981; Mancktelow, 1987; Law et al., 1990). The same type of transition of $[c]$-axis pole figures from peripheral maxima via a girdle to a central maximum has also been observed within metamorphic gradients (Stipp et al., 2002) and used to infer the metamorphic conditions during deformation (see Law, 2014, for a review). A potential relation between temperature and different types of $[c]$-axis pole figures has been encouraged by speculations about a temperature de- 
(a)

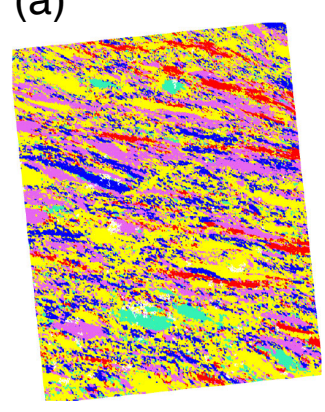

(b) Regime 1

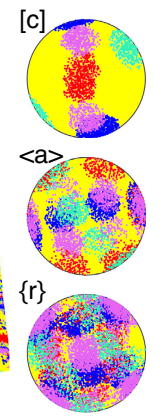

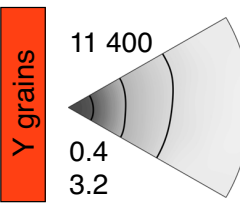

뜬
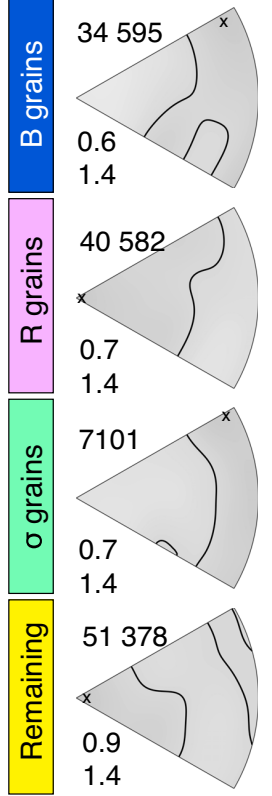
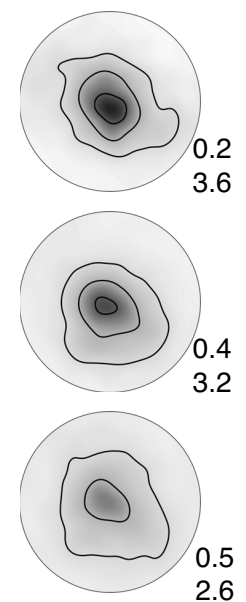

2.6
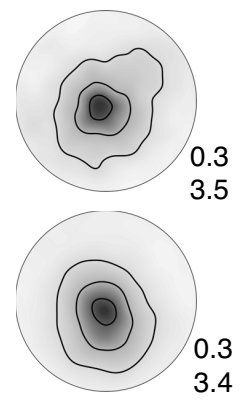

Regime 2

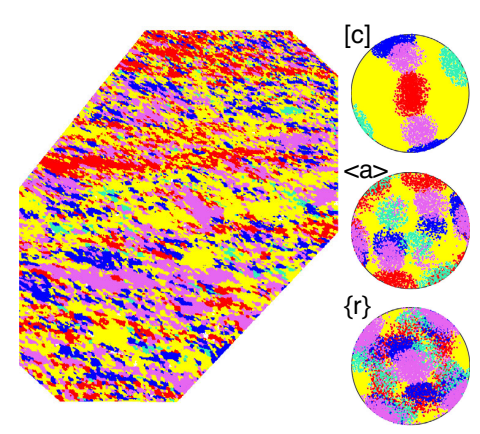

Regime 2

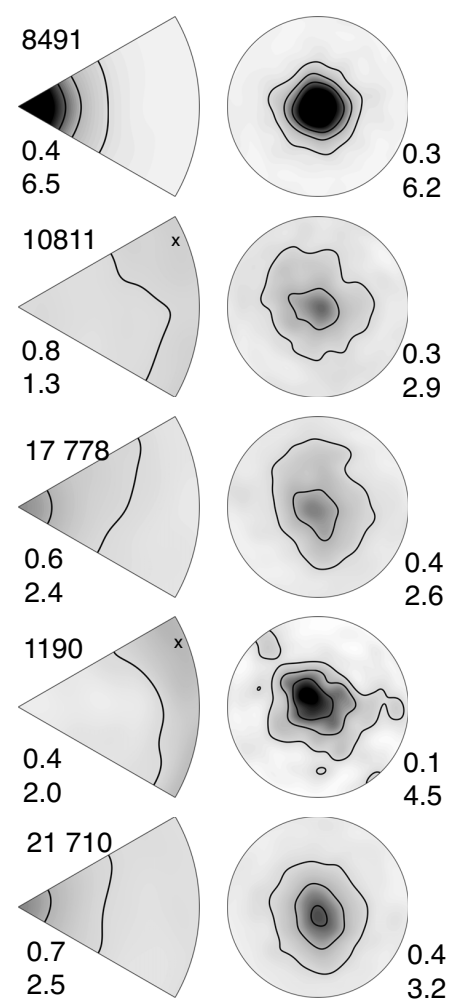

Regime 3

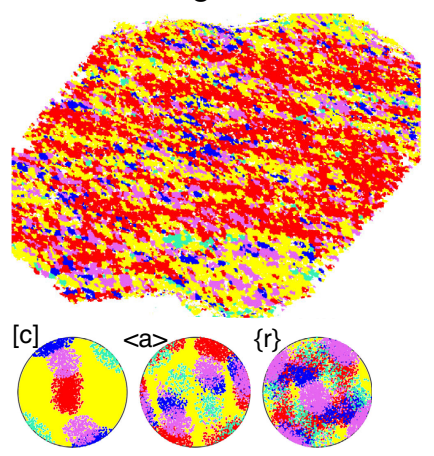

Regime 3

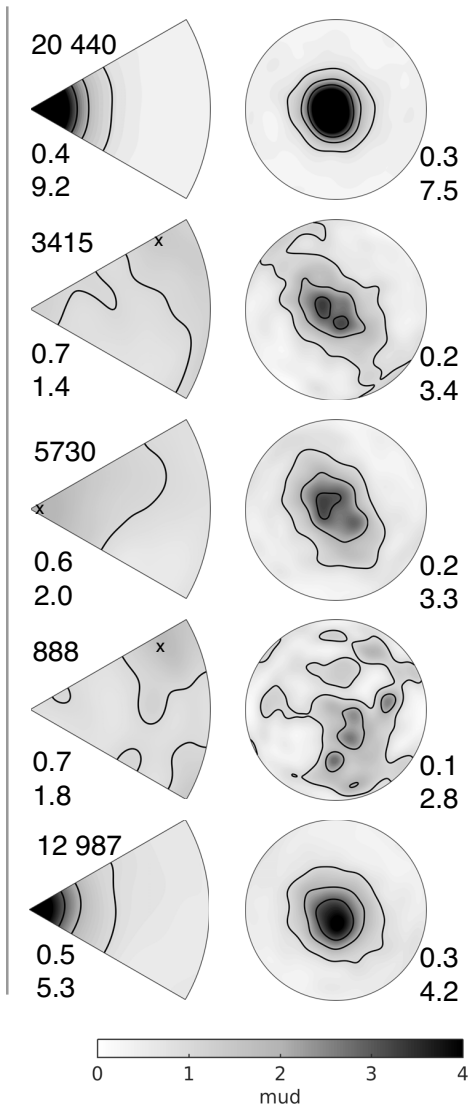

Figure 9. Misorientation axes and texture domains. (a) Maps of texture domains defined within $25^{\circ}$ with respect to the orientations forming local maxima in the ODF, color-coded in red (Y grains), blue (B grains), pink (R grains), green ( $\sigma$ grains) and yellow (all other grains). Pole figures for $[c],\langle a\rangle$ and $\{r\}$, illustrating the position of individual texture domains. (b) Density-contoured plots for misorientation axes of low-angle boundaries (misorientation angles of $2-9^{\circ}$ ) in crystal and specimen coordinates. Density contours at steps of 1 times the uniform. Crosses indicate the highest densities in the low-density plots. Numbers below plots indicate the minimum-maximum density range and the number of orientation pairs (upper left).

pendency of different $\langle a\rangle$-slip systems (Blacic, 1975; Hobbs, 1985). However, there are texture measurements from naturally deformed quartz mylonites that cannot be easily explained by the temperature dependency of different $\langle a\rangle$-slip systems (Toy et al., 2008; Pennacchioni et al., 2010). In addition, in experimentally deformed quartz rocks, $[c]$-axis girdle-to-central maximum (Heilbronner and Tullis, 2006) or peripheral point-to-central maximum transitions (Cross et al., 2017) have been reported for strain gradients within 


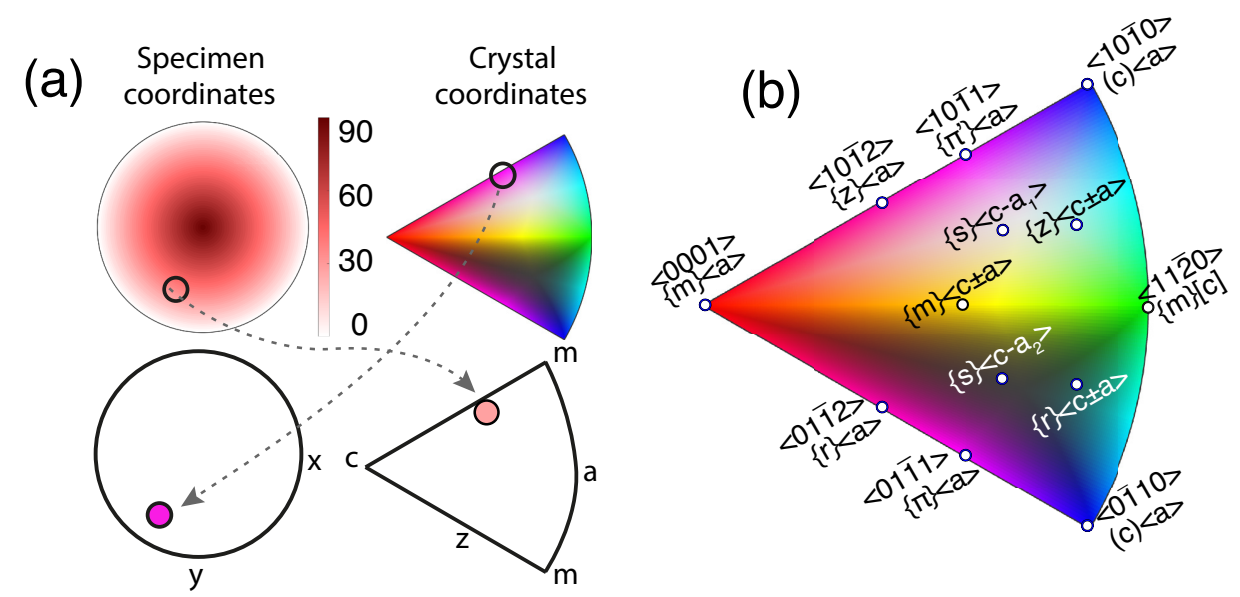

(c)

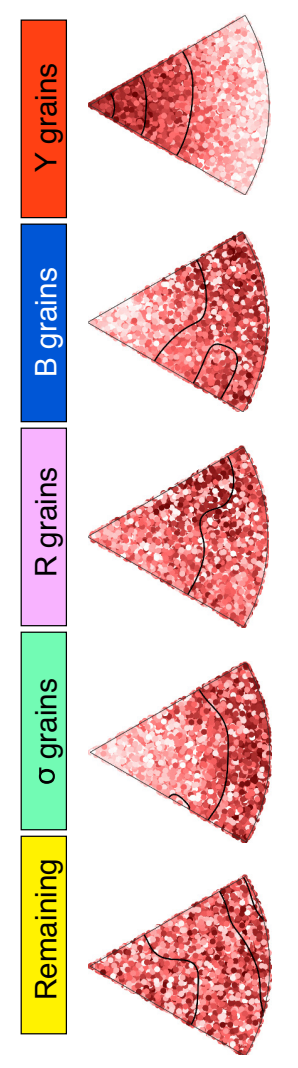

Regime 1

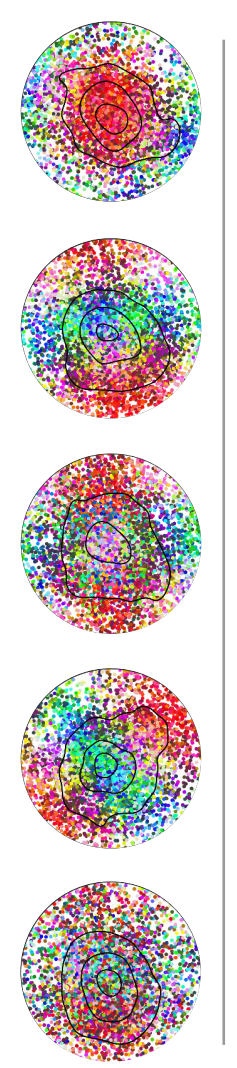

Regime 2

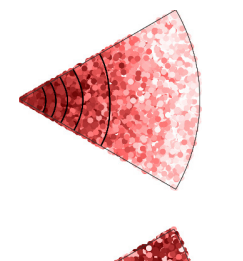

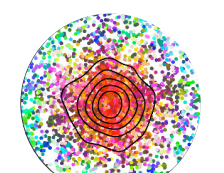
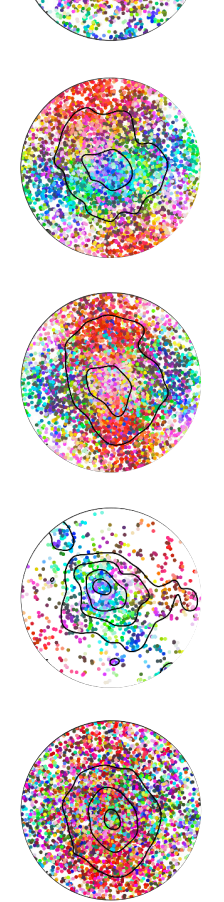

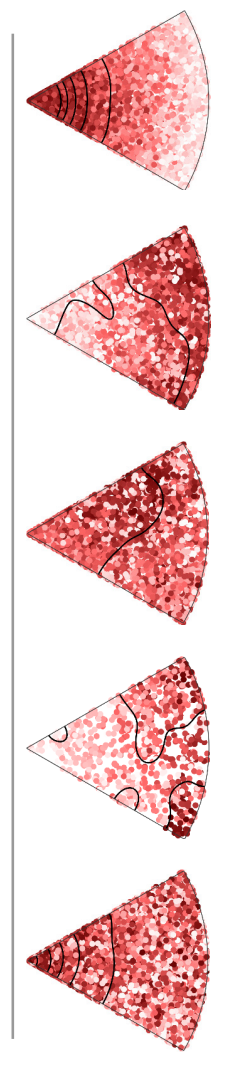

Regime 3
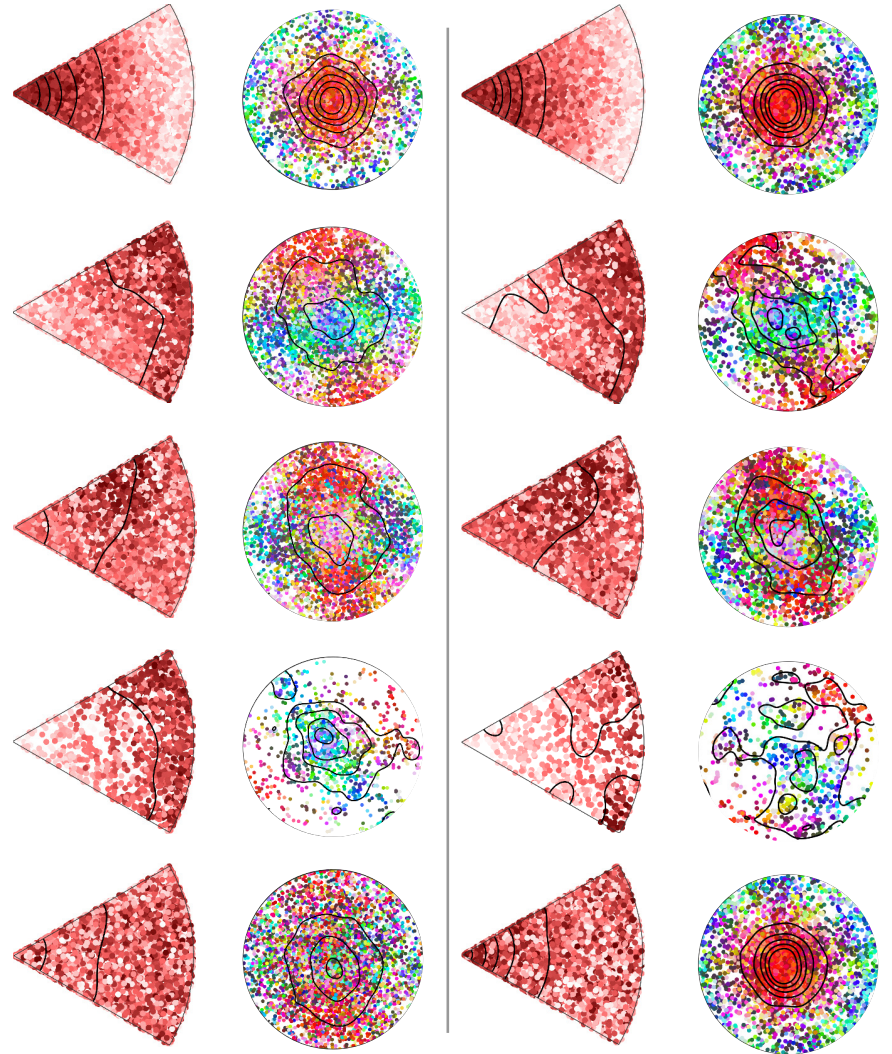
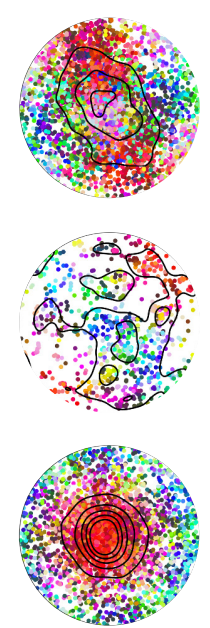

Figure 10. Misorientation axes and texture domains. Data are identical to Fig. 9. (a) Color-coding scheme used for misorientation axes relating axes in specimen and crystal reference frame (see main text for details). (b) Coloring used for crystal coordinates; rotation axes for pure tilt boundaries are indicated for a few selected slip systems. (c) Point plots of misorientation axes using the coloring scheme in (a); for large number datasets, only 5000 randomly selected axes are displayed.

individual samples, an observation also incompatible with a purely temperature-dependent texture development.

In the high-strain experiments analyzed here, the temperature range was considerably small $\left(850-915^{\circ} \mathrm{C}\right)$, and displacement rates and finite strains were approximately identi- cal in all regimes. The major difference for these samples is the peak and flow stress, which is mediated by the addition of water (Table 1). Accordingly, the effects of flow stress, and consequently of recrystallization, grain-scale strain and 

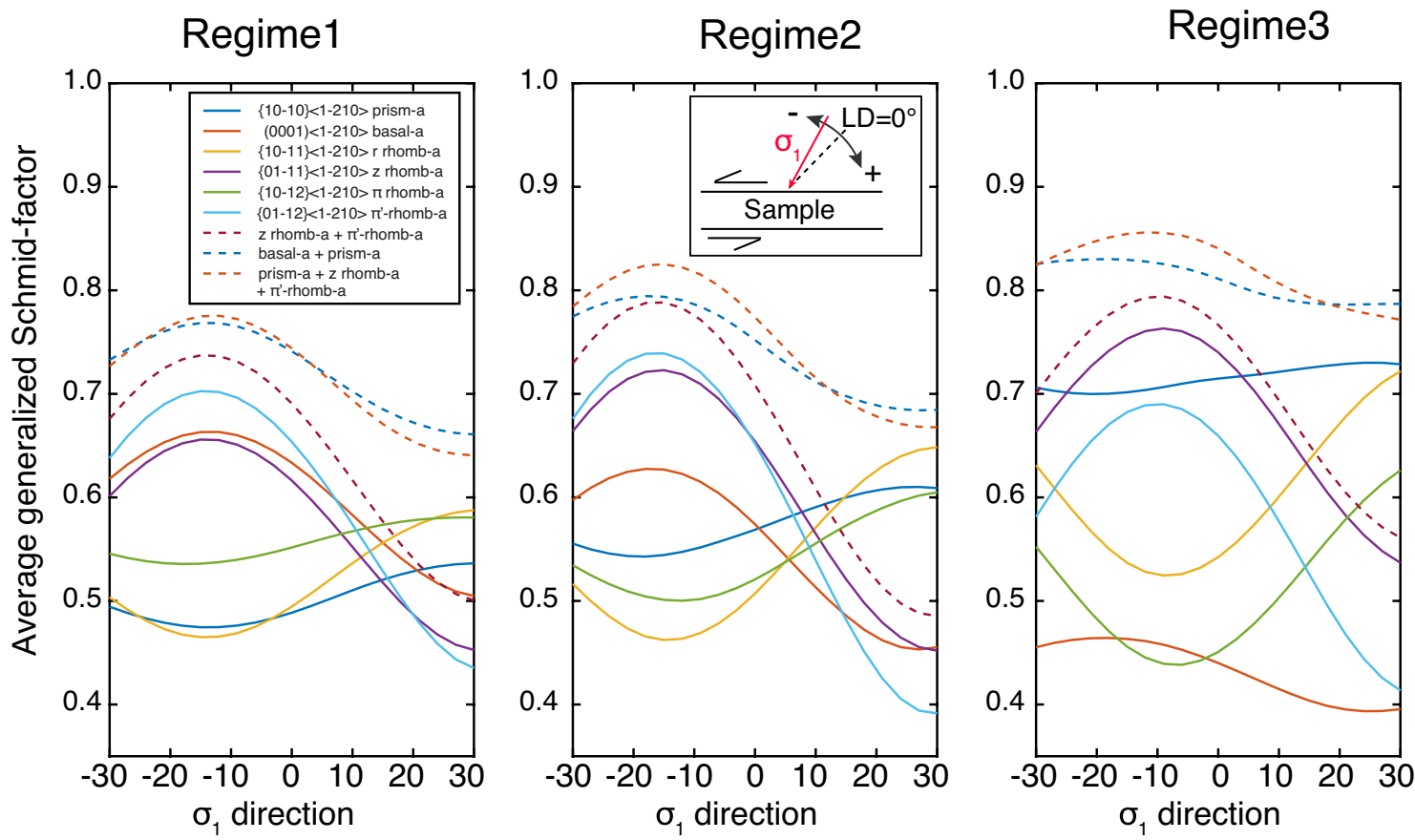

Figure 11. The average, generalized Schmid factor shown for different slip systems (or combinations of slip systems) as a function of the trend of $\sigma_{1}$ of a triaxial stress tensor. On the $x$ axis, $0^{\circ}$ corresponds to a $\sigma_{1}$ direction parallel to the loading direction; negative and positive angles correspond to synthetic or antithetic rotations of the stress tensor (see inset).

texture-forming processes need to be considered as critical parameters for the texture transition observed.

\subsection{Texture transition and deformation}

On the sample scale, a dependence of the texture transition on strain is evident from the comparison of the regime 3 lowand high-strain samples. However, the dependence of the texture transition on strain can also be verified along strain gradients with the high-strain samples of the three regimes. The $\theta-R$ relation and the gKAM are taken as a measure for deformation at the grain scale. Increasing grain-scale deformation correlates with higher central densities along (partial) $[c]$-axis girdles. On average, the grain shapes seem to correlate with deformation since the $\theta$ maximum coincides with the $\mathrm{ISA}_{1}$ and the most synthetically rotated $[c]$-axis girdles are found in the $\theta$ classes, which contain the direction of the long axis of the finite strain ellipsoid (Fig. 5b). Similarly, the gKAM is an expression of the intragranular deformation intensity, assuming that strain on the grain scale is achieved via a dislocation mechanism and that low-angle boundaries are the result of dynamic recovery by climb of the strainproducing dislocations. Additionally, the gKAM can be used to visualize that grain-scale strain is related to the strain gradient in the samples (Fig. 7b). If it can be accepted that the grain-shape fabric and the gKAM indicate deformation, the increasing density of $[c]$ axes in the pole figure skeleton away from the periphery, the development and strengthening of a girdle component, and/or the formation of a central maximum can all be related to deformation. Based on the change in shape of the pole figure skeleton, and based on an increase in texture strength with increasing grain-scale deformation, dislocation glide is considered to be the process which links deformation of grains and texture development.

The more highly deformed the grains in each regime, the further away from the periphery of the pole figure the $[c]$ axes. Given that the BHQ starting material has a uniform texture, it is suggested that the $\mathrm{Y}$ maximum is strain induced, with the $[c]$ axes progressively rotating along the single girdle towards the center of the pole figure while the $\langle a\rangle$ axes remain in a relatively stable position. This interpretation is compatible with the observations in nature (Pennacchioni et al., 2010), experiments (Heilbronner and Tullis, 2006; Cross et al., 2017) or kinematic models for [c]-axis trajectories (Urai et al., 1986).

However, while the strain-dependent texture development can be used to explain the differences between the low- and high-strain regime 3 samples as well as variations inside each sample, it cannot account for the complete texture transition between regime 1 and regime 3 experiments, all deformed roughly to the same strain. The high volume of B domains in regime 1 but also in the low-strain regime 3 sample must have developed from the uniformly textured BHQ. Because all strain-related effects on the texture seem to drive $[c]$ axes away from the periphery, the occurrence of B domains calls 
for an additional process influencing the texture development.

\subsection{Deformation and recrystallization mechanisms}

In order to better understand the processes involved during deformation of the samples, the deformation and recrystallization processes involved are discussed. The strength of the texture in a deformed rock is a function of the contribution of different processes and the strain these processes accommodated. Therefore, the texture strengths produced by dislocation glide as a texture-forming process and grain boundary sliding as a texture-weakening process have to be compared quantitatively. The concurrent operation of dislocation creep and grain boundary sliding is well known from metals (e.g., Kottada and Chokshi, 2007) and has also been suggested for quartz mylonites (Mancktelow, 1987; Kilian et al., 2011a). Grain boundary sliding as a strain-producing mechanism on its own can be expected as long as the grain size remains smaller that the subgrain size (Langdon, 1994).

The texture strength increases from regime 1 to regime 3 as well as with increasing grain-scale deformation (Fig. 8). In both cases, the increase can be related to the contribution of crystal plastic, texture-producing mechanisms such as dislocation glide and climb. The evidence for texture-weakening processes (e.g., grain boundary sliding) is more subtle. In regime 1 , small grains have $[c]$ axes broadly dispersed along the periphery (Fig. 5), which is compatible with grain rotation about the vorticity axis. With increasing $R$ and $d$ of the recrystallized grains, $[c]$ axes gather towards the peripheral edge of a partial single girdle. Low-gKAM grains show the broadest dispersion of $[c]$ axes at the periphery (Fig. 7). Another indication of grain boundary sliding is the observation that grains and their crystal orientation are not entirely independent as shown by the correlation of the $[c]$-axis girdle trend with $\theta$ (Fig. 5). This correlation suggests that in general the rotation rates of grains are not completely balanced by the rotation of crystal axes, such that grains rotate "with" their crystal orientation, a process requiring grain boundary sliding.

In regime 1, bulging recrystallization (BLG) is thought to be the predominant recrystallization mechanism (Hirth and Tullis, 1992; Stipp and Kunze, 2008). The resolution of our EBSD data does not allow us to confirm that the microstructure is one of BLG. The textural characteristics, however, confirm a rapid loss of host control, a feature commonly related to BLG. The exact nature of the process that controls the orientations of newly formed grains during BLG is still unclear. There are different suggestions such as subgrain rotation of bulges followed by grain boundary sliding (e.g., Halfpenny et al., 2006; Stipp and Kunze, 2008) or lattice rotation caused by shear-induced grain boundary migration (Cahn and Mishin, 2009). Oriented nucleation and growth may have to be considered as a mechanism for the formation of new grains, as indicated by the presence of shear-band-like features with $[c]$ axes aligning roughly with the stretching direction or the opening direction of shear bands (Fig. 4).

In regime 2 and regime 3 (high-strain samples), surviving large grains usually show systematic substructures characterized by discrete orientation domains of a size comparable to small recrystallized grains. In addition, orientation domains that are approximately the size of original BHQ grains (Heilbronner and Kilian, 2017, this volume) but are fully recrystallized are recognized. The progressive change in grain orientation with respect to the grains' neighbors in $\mathrm{Y}$ domains in regime 3 is compatible with the rotation of parts of the crystal around misorientation axes parallel to the vorticity axis inferred for the experiment. All these microstructures are compatible with SGR.

From these observations, the contribution of dislocation creep is interpreted to be highest in regime 3 and the contribution of grain boundary sliding is highest in regime 1 . Since all mechanisms operate concurrently, observed changes in texture strength are a result of a different contribution of each individual process (regime 1 to regime 3 ) and bulk strain (regime 3 low strain to high strain). Regime 2 is interpreted as transitional - more dislocation creep than in regime 1 and more grain boundary sliding than in regime 3 .

In the regime 1 sample analyzed, a large fraction of recrystallized grains attain an orientation unrelated to the original orientation of the BHQ grains. While grain boundary sliding may contribute to the dispersion of orientations of newly recrystallized grains away from the host orientation, it is not a process that initially develops grains with $[c]$ axes close to the periphery. Similarly, samples with a low texture strength show a very strong clustering of poles to $\{r\}$ and $\{\pi\}$ parallel to the $\mathrm{ISA}_{2}$, with $\{r\}$ close to the elastically softest direction. This effect is the result of Dauphiné twinning caused by a rotation of $\{z\}$ away from the instantaneous shortening direction around $[c]$. Accordingly, Dauphiné twinning cannot account either for a preferred development of grains with peripheral $[c]$ axes, and the occurrence of $\{r\}$ clusters may simply be an effect of the low texture strength.

Small, equiaxed grains are systematically found at two conjugate, peripheral $[c]$-axis positions (Fig. 6). One of those positions pertains to grains grown in the shear-band-like features (Fig. 4), the other being at a high angle to the shear plane, inclined against the sense of shear and more easily recognized in the pole figures (Figs. 5, 6). These positions can be found for regime 2 but they are less pronounced for regime 3 . While on average there is a tendency for those grains to form with specific $[c]$-axis directions, this initial orientation is easily modified by grain boundary sliding or dislocation glide. Larger recrystallized grains deviating from those orientations are usually associated with a higher gKAM, a higher texture strength and an off-periphery $[c]$-axis direction. These grains can be regarded either as "overprinted" by a crystal plastic mechanism while grains grow or as having formed by a different dynamic recrystallization process such as geometric dynamic crystallization, for example. We will consider the 
initial development of grains with $[c]$ axes at peripheral directions to be related to nucleation and/or growth, which will be further discussed in Sect. 4.3.2.

\subsubsection{Evidence of active slip systems}

Quartz [c]-axis pole figures are frequently used in the literature to make assumptions about the slip systems involved during deformation. With regard to the texture transition observed in the experimentally deformed BHQ, the regime 1 and regime 3 low-strain samples are usually associated with (c) $\langle a\rangle$ slip, while the regime 3 high-strain samples are related to $\{m\}\langle a\rangle$ slip. To test these assumptions, misorientation axes were analyzed for different texture domains. Even though the interpretation of slip systems based on misorientation axes carries uncertainties due to the fact that the 3-D orientation of subgrain boundaries cannot be fully derived from 2-D sections, and while it is not clear whether the strainproducing dislocations are those that also contribute most to subgrain boundaries, misorientation axes supply more information compared to speculations solely based on pole figures or deformation lamellae. In the $\mathrm{Y}$ domains, most misorientations (Fig. 9) are compatible with a dominance of a $\{m\}\langle a\rangle$ slip system, and since axes in specimen coordinates coincide with the inferred vorticity axis, there is a high probability of a tilt character for boundaries trending parallel to $\{11 \overline{2} 0\}$. In the $\mathrm{R}$ domains, misorientation axes parallel to the vorticity axis correspond to axes of tilt boundaries of $\left\{\pi^{\prime}\right\}\langle a\rangle,\{z\}\langle a\rangle$ and $\{s\}\langle c-a\rangle$ slip systems. While the former two slip systems have been identified in nature (e.g., Morales et al., 2011) and experiments (e.g., Linker et al., 1984), and have been suggested based on texture and Schmid factor considerations (Law et al., 1990), the large Burgers vector associated with $\langle c \pm a\rangle$ renders the latter one a rather hard and unlikely slip system. The entire misorientation-axis distribution shows a strong superposition with $[c]$ misorientation axes, suggesting that in R domains oblique activation of $\{m\}\langle a\rangle$ and $\{z\}\langle a\rangle$ or $\left\{\pi^{\prime}\right\}\langle a\rangle$ operate together. This interpretation is compatible with the persistence of an $\langle a\rangle$ alignment while $[c]$ changes its position along the kinked girdle.

The misorientation axes of the B domain show a distribution close to uniform. In the case of $(c)\langle a\rangle$ activity and the presence of tilt boundaries, misorientation axes are expected to be clustered around $\langle 10 \overline{1} 0\rangle$ and in the case of conjugate $\langle a\rangle$ slip, they should disperse along the trace of the basal plane. In the case of twist boundaries, the rotation axes would be expected to be parallel to $[c]$. As very little of this is observed, we conclude that $(c)\langle a\rangle$ is not one of the most active slip systems in the B domain. Notably, the elliptical shape of the misorientation-axis distribution in specimen coordinates is not only found in $\mathrm{R}$ domains but also in several $\mathrm{B}$ and $\sigma$ domains, in which the elongation is found to be parallel to the trace of the $[c]$ axis. Accordingly, we interpret that composite slip of $\left\{\pi^{\prime}\right\}\langle a\rangle,\{z\}\langle a\rangle$ and $\{m\}\langle a\rangle$ occurs in all those domains.
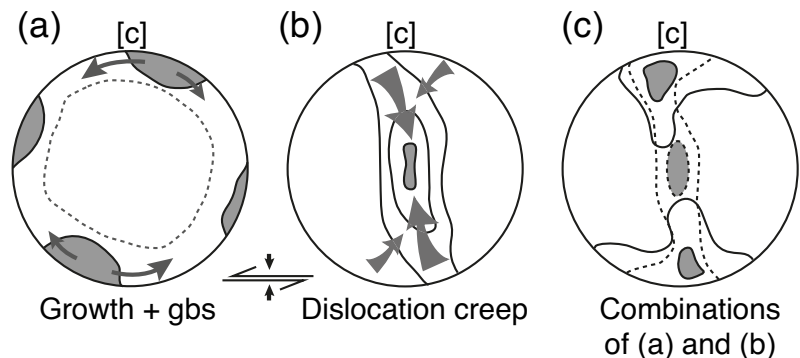

Figure 12. Conceptual model of the development of a crystallographic preferred orientation during general shear. (a) $[c]$-axis positions of newly grown grains (gray areas) and subsequent dispersion associated with grain boundary sliding (arrows, stippled line). (b) $[c]$-axis positions formed during dislocation glide along multiple $\langle a\rangle$ slip systems. Gray arrows indicate the path of $[c]$-axis migration with (grain-scale) strain. (c) Two possible $[c]$-axis pole figures formed by a combination of the end-member processes in (a) and (b) from a randomly oriented starting material. Large contributions of grain boundary sliding lead to a broad peripheral $[c]$-axis distribution of newly grown grains, and subordinate dislocation glide contributes to a partial girdle and off-periphery maxima - a situation encountered in high-stress experiments or generally at low strain. Large contributions of dislocation glide lead to a high density of $[c]$ axes in the center of the pole figure (stippled line), and only few newly grown grains from the periphery contribute to the peripheral part of the girdle.

The interpretation above corroborates with the Schmid factor analysis (Fig. 11), in which overall high Schmid factors are found for $\left\{\pi^{\prime}\right\}\langle a\rangle,\{z\}\langle a\rangle$ and in regime 3 for $\{m\}\langle a\rangle$, with a direction of the maximum principal stress axis aligned with the ISA 2 .

\subsubsection{A model for the texture development and texture transition}

As outlined above, a deformation-dependent rotation of $[c]$ axes away from the periphery of the pole figure is observed. It is also inferred that $\{m\}\langle a\rangle,\{z\}\langle a\rangle$ and $\left\{\pi^{\prime}\right\}\langle a\rangle$ slip systems operate together and evidence of $(c)\langle a\rangle$ is scarce. Conversely, there is no indication that any of the processes and mechanisms described above contribute to the presence of grains with $[c]$ at the periphery of the pole figure, which is the texture encountered in the regime 1 and regime 3 lowstrain samples.

The principal difference in that suite of experiments is the sample strength, mostly controlled by the amount of water added to the sample assembly, a technique well known to modify the strength of experimentally deformed quartzites (e.g., Kronenberg and Tullis, 1984; Jaoul et al., 1984). Despite early speculations that different water contents (or any sort of hydrous defects) may have an influence on the activity of specific slip systems (e.g., on synthetic single crystals; Blacic, 1975), the amount of water present in the as-is samples is still sufficiently large to hydrolyze all dislocations 
even at high densities (Paterson, 1989; Stipp et al., 2006) and, hence, the overall weakening effect will be the result of enhanced recovery processes. The role of water in experimentally deformed, polycrystalline quartz aggregates is mainly related to the control of grain boundary mobility (e.g., Gleason et al., 1993; Stipp et al., 2006), which is also suggested for naturally deformed rocks (e.g., Mancktelow and Pennacchioni, 2004; Kilian et al., 2016). Accordingly, a direct relation of water content to the texture transition through a dislocation mechanism is excluded here.

We suggest a model in which the texture transition can be explained (a) by the motion of [c] during SGR and dislocation glide towards the center of the pole figure along welldefined paths into the girdle and (b) by an additional process operating at high differential stress levels producing new grains with $[c]$ at the periphery of the pole figure (Fig. 12a, b). Both texture-forming processes compete, with the first one being dominant in regime 3 and the second one being dominant at high stresses in regime 1 . Regime 2 is a transition in which both contributions might be roughly balanced. Depending on the relative contribution of these processes and on strain, either a girdle, central Y maximum or a peripheral maximum is developed.

In regime 3, SGR is the most active and fastest recrystallization process, and glide-induced rotation of $[c]$ towards the $Y$ direction is rapid. The formation of new grains is subordinate and not many new grains are formed with $[c]$ at the periphery. All large grains are recrystallized in the high-strain experiments. In the low-strain experiment of regime 3, the formation of new grains is active at low-stress conditions, and while strain produced by dislocation creep is not high, the texture related to the formation of new grains is not (yet) entirely obliterated. In regime 1, the formation of new grains is dominant and SGR is slow. The matrix of small grains deforms with a large contribution of grain boundary sliding; hence, the rotation of $[c]$ towards the center is slow and $[c]$ is dispersed along the periphery. Since strain partitions into the matrix, porphyroclasts that stretch most effectively are those that survive longest. Several lines of evidence support a mechanism such as the formation of new grains by nucleation and/or growth. For example, the growth of new grains after fracturation in highly strained crystals under non-hydrostatic stresses can result in a moderate to strong crystal preferred orientation in deformation experiments (e.g., Hobbs, 1968; Gleason et al., 1993; Vernooij et al., 2006; Trepmann et al., 2007; Trepmann and Stoeckhert, 2013) and in nature (e.g., Hippertt, 1994; Hippertt and EgydioSilva, 1996; Menegon et al., 2008; Kjoll et al., 2015). Newly formed grains are found to have $[c]$ parallel and occasionally orthogonal to the (inferred) shortening direction (e.g., Hobbs, 1968; Gleason et al., 1993; Trepmann and Stoeckhert, 2013; Kjoll et al., 2015 ) or at $\sim 45^{\circ}$ to the stretching direction of shear fractures (e.g., Vernooij et al., 2006; Trepmann et al., 2007; Menegon et al., 2008). Fracture and microfracture development have been documented in the Griggs apparatus, even at high confining pressures and temperatures, and are thought to be an essential process that accompanies or enables crystal plastic deformation in the experiments (Fitz Gerald et al., 1991; Denbrok and Spiers, 1991; Stunitz et al., 2017). This probably also applies to BHQ during the initial steps of deformation or generally to quartzites deforming in a hardening regime with limited grain boundary mobility (Hirth and Tullis, 1992).

We do not have direct evidence of a fracture, nucleation and/or growth origin of the newly formed grains in regime 1 ; however, in most experimental studies B domains seem to be the first to form at high-stress conditions. Our model also explains the texture transition observed by Tullis et al. (1973), with preferred growth of $[c]$ parallel to the shortening direction in the high-stress experiments and $[c]$ axes forming a small circle centered around the compression axis in the low-stress regime. Whether the resulting texture in regime 1 relates to oriented nucleation, anisotropic growth under non-hydrostatic stresses, the elastic anisotropy of quartz and whether it is (additionally) influenced by the local kinematics are the topics of future studies. What we can conclude here is that in a high-driving-force environment (high stress, high dislocation density), the presence of B domains is not related to $(c)\langle a\rangle$ slip.

\subsection{Does basal $\langle a\rangle$ slip give rise to peripheral $[c]$ axes?}

Textures with peripheral $[c]$ axes are often observed in rocks deformed under low-grade conditions. Based on the postulated temperature dependence of $\langle a\rangle$ slip systems (e.g., Hobbs, 1985), it was assumed that $(c)\langle a\rangle$ may operate readily at low-temperature conditions. The expectation that $(c)\langle a\rangle$ is an easy slip system in quartz relies on studies that did not actually demonstrate the existence of $(c)\langle a\rangle$ as an easy slip system (e.g., Lister, 1979). In early studies, the interpretations of the activity of $(c)\langle a\rangle$ and its contribution to strain are based on the presence of deformation lamellae as well as macroscopic features documented for experiments conducted at very high differential stresses (e.g., Christie et al., 1964; Christie and Green, 1964; Heard and Carter, 1968; Baeta and Ashbee, 1969; Avelallemant and Carter, 1971; Ardell et al., 1974). The assumption that deformation lamellae represent slip planes has been revised and rejected several times (e.g., McLaren and Hobbs, 1972; White, 1973; Drury, 1993). Many transmission electron microscope (TEM)-based studies find indications for $\langle a\rangle$ slip on $\{m\},\{z\}$ and $\left\{\pi^{\prime}\right\}$, while evidence for $(c)\langle a\rangle$ slip is missing (Christie and Green, 1964; Morrison-Smith et al., 1976; Twiss, 1976; Gapais and White, 1982; McLaren et al., 1983; Linker et al., 1984). Many studies find that $(c)\langle a\rangle$-related dislocation systems are not dominant at all or are pinned and likely of very limited mobility unless deforming by climb (Trepied and Doukhan, 1978; Doukhan and Trepied, 1979; Trepied et al., 1980; Mainprice et al., 1986; Mainprice and Jaoul, 2009; Morales et al., 2011). Nevertheless, many studies still claim that $(c)\langle a\rangle$ is an effi- 
cient or easy slip system in quartz, directly citing some of the studies above - which actually do not demonstrate the activity of $(c)\langle a\rangle$ - or referring to publications that themselves relate to sources that never demonstrated the ease of $(c)\langle a\rangle$. As an alternative, many studies rely on the purely geometrical suitability and the assumption that sufficiently large crystal plastic strains can be realized on $(c)\langle a\rangle$ (e.g, Tullis, 1977; Bouchez and Pecher, 1981; Schmid and Casey, 1986; Heilbronner and Tullis, 2006; Stipp et al., 2002; Kilian et al., 2011b). Numerical texture modeling (e.g., Lister, 1979) cannot be taken as evidence that $(c)\langle a\rangle$ slip actually happens to be the process that drives $c$ axes to the periphery of the pole figure in quartz. In fact, newer studies, based on TEM observations in conjunction with numerical texture modeling, suggest that the presence of peripheral $[c]$ axes does not necessarily require the dominant activity of $(c)\langle a\rangle$ (Morales et al., 2011). It is beyond the scope of this contribution to revise the literature on quartz slip systems in detail, but we note the scarceness of direct evidence of $(c)\langle a\rangle$ in contrast to other slip systems with $\langle a\rangle$ as a slip direction. We therefore feel justified raising some doubt concerning the common assumption that $(c)\langle a\rangle$ slip contributes to large crystal plastic strains and that the presence of $B$ domains is indicative of the activity of $(c)\langle a\rangle$ slip.

\subsection{Implications for interpretation based on quartz $c$-axis data}

The analysis presented yields several implications with respect to the applications of quartz textures for the analyses of deformed rocks, in particular with respect to the interpretation of deformation temperatures. In nature, microstructural transitions in which different recrystallization processes developed over a metamorphic gradient have been documented (Stipp et al., 2002). From this a correlation of temperature, or recrystallization processes, with a specific type of texture was conducted. Many Y-maximum textures in natural quartz mylonites develop where the recrystallization mechanism is mainly SGR, with only minor involvement of grain boundary migration recrystallization (GBM) (e.g., Mancktelow, 1987; Fitz Gerald et al., 2006; Pennacchioni et al., 2010), while in the original publication of Stipp et al. (2002) Y domains started to appear in the GBM regime only. Given our observation of the intensification of the $\mathrm{Y}$ maximum with increasing deformation intensity at constant temperature conditions, the observations in nature are more readily interpreted as a function of total strain instead of a texture dependence on SGR or GBM. Our interpretation is supported by studies on naturally mylonitized quartz veins with a good control on strain (Pennacchioni et al., 2010), in which a texture evolution that is similar to regimes $2-3$ transitions presented here is observed. Examples of B-domain textures observed at very high temperatures (e.g., Menegon et al., 2011) probably do not indicate an abnormal activity of $(c)\langle a\rangle$ but rather a high stress, texture-forming mechanism similar to the formation of new grains as suggested here. With relation to temperature determinations, we can also note that within the experiments presented, a range of $[c]$-axis opening angles can be found (Fig. 5). The observation that this opening angle seems to vary as a function of grain shape may have the potential to add more complexity to the $[c]$-axis opening angle thermometer.

In addition to the formation of new grains by nucleation and growth (dominant in regime 1) and by SGR (dominant in regime 3), contributions of grain boundary sliding (possible in all regimes) may challenge our understanding of the grain size-stress relation with respect to piezometric applications. Together with the grain size-gKAM relation documented in the companion paper (Heilbronner and Kilian, 2017, this volume), this makes a unique dependence of grain size on stress seem less and less likely.

\section{Summary and conclusions}

To study the textures (crystallographic preferred orientations) of Black Hills Quartzite, deformed in general shear in regimes 1, 2 and 3, EBSD data were analyzed using a number of new methods for combined texture and microstructure analysis.

The textures of all regimes are dominated by the alignment of $\langle a\rangle$ with the direction of maximum shear stress. Samples sheared to identical high strains show characteristically different $[c]$-axis pole figures: peripheral maxima in regime 1 , a kinked single girdle in regime 2 and a central maximum in regime 3 . A low-strain regime 3 sample shows a texture comparable to a high-strain regime 1 sample. On the basis of the analysis presented we propose a new interpretation concerning texture formation and texture transition, as well as concerning the relation between $[c]$-axis orientation and active slip systems. Of the three dislocation creep regimes, only regimes 1 and 3 are considered distinct, with regime 2 being transitional.

- Recrystallization in regime 3 happens by subgrain rotation recrystallization, and deformation occurs through dislocation creep with a minor contribution from grain boundary sliding. Porphyroclasts in all regimes deform by dislocation glide and climb. The texture varies as a function of grain size, grain lengthening, long-axis alignment and gKAM. $[c]$ axes occupy positions increasingly further away from the periphery of the pole figure as deformation intensity on the grain and sample scales increases. This change in pole figure skeleton shape is accompanied with a strengthening of the texture. The increasing texture strength is interpreted as a decreasing contribution of grain boundary sliding and an increasing contribution of dislocation glide and climb. 
- Differences in experimental temperatures and strain rates are negligible, while the water-moderated stress level varies between 100 and $>300 \mathrm{MPa}$. In the highstress regime there is no observation of a rotation of $[c]$ towards the periphery of the pole figure with strain (only away from it). We therefore propose an additional texture-forming process, i.e., nucleation and or growth of new grains, to be responsible for the formation of grains with peripheral $[c]$ axes.

- The finite texture balances the contributions of dislocation glide on several $\langle a\rangle$ slip systems (during which $[c]$ is attracted towards the center of the pole figure as a function of strain) and new grains formed at the periphery of the pole figure, their amount being controlled by the stress level. Newly formed grains subsequently grow and deform and the texture presents a dynamic balance between both processes. According to our interpretation, a temperature dependency of quartz textures is only indirect, while the relative contribution of the two texture-forming processes are the controlling factors.

- The hypothesis that $(c)\langle a\rangle$ slip is responsible for peripheral $[c]$ maxima, $\{m\}\langle a\rangle$ slip for the central Y maximum, and only $\left\{\pi^{\prime}\right\}\langle a\rangle$ or $\{z\}\langle a\rangle$ for the symmetrically disposed $\mathrm{R}$ maxima cannot be confirmed. While maxima of distributions of misorientation axes always lie parallel to the vorticity axis, individual misorientation axes giving rise to these maxima are indicative of $\{m\}\langle a\rangle,\left\{\pi^{\prime}\right\}\langle a\rangle$ and $\{z\}\langle a\rangle$ activity for a wide range of $[c]$-axis inclinations.

- That the peripheral $[c]$ axes are not uniquely related to dislocation glide of $(c)\langle a\rangle$ is additionally supported by the analyses of Schmid factors. We propose that the common notion of $(c)\langle a\rangle$ as an efficient slip system in quartz should be critically re-evaluated.

Code availability. The MTEX function to calculate the gKAM can be found here: https://gist.github.com/kilir/ ce22bebfcc7d15acaf75e6b76b8517ed. 


\section{Appendix A: Methods}

\section{A1 Spherical interpolation of grain properties}

Grain properties were interpolated in $[c]$-axis pole figure space (Fig. 6). In order to avoid a bias introduced by the uneven distribution of $[c]$-axis poles, the following procedure was used: a subsample of 400 grains was drawn, the $[c]-$ axis direction was calculated, the property associated with each grain was interpolated on a $15^{\circ}$ spherical grid using an inverse distance weighting and the procedure was repeated 1000 times. The mean of all interpolations was then plotted as a pole figure.

\section{A2 Quantitative comparison of texture strength}

The estimated texture strength of a given set of orientations depends on a proper kernel width and since kernel width estimators should always be conservative, the texture strength, when properly calculated, will not be overestimated. Conversely, this makes it difficult to compare textures based on very different numbers of orientations. In those cases, an estimation based on the same number of orientations with a fixed kernel width is more suitable for a quantitative comparison. In order to compare texture strength of the grain property classes (e.g., grain size-aspect ratio classes), subsets of orientations with identical sizes were estimated in a bootstrapping approach. Within a property class, 100 randomly chosen subsets of the size of the smallest of any population (>100) were repeatedly drawn from the population of grains. Texture parameters were calculated for each subset using a constant kernel width. The mode of the resulting distributions is compared. The standard deviation usually converged after $<50$ draws to below $5-10 \%$. The texture parameters evaluated are the texture index and two fiber volumes. A fiber volume is the mass fraction of an ODF contained within a radius around a line in ODF space that is given by a crystal direction and a corresponding specimen direction. A B fiber is defined by the [0001] direction inclined $76^{\circ}$ to the shear plane with the sense of shear (corresponding to the $\mathrm{B}$ domains), and the Y fiber is defined by the [0001] direction pointing towards the center of the pole figure (corresponding to the $\mathrm{Y}$ domains). For easier inspection and comparison, results are color-coded and plotted in $\mathrm{x}-\mathrm{y}$ parameter space (aspect ratio-grain size or $\theta$-aspect ratio; Fig. 8). 
Competing interests. Renée Heilbronner is a member of the editorial board of the journal.

Special issue statement. This article is part of the special issue "Analysis of deformation microstructures and mechanisms on all scales". It is a result of the EGU General Assembly 2016, Vienna, Austria, 17-22 April 2016.

Acknowledgements. We wish to thank Jan Tullis for letting us use her thin sections again. We are also grateful to Tom Eilertsen, Kai Neufeld and Michel Bestman for support and advice during EBSD image acquisition at Troms $\varnothing$ University. The comprehensive reviews by Luiz Morales and Dave Prior are greatly appreciated; they helped to improve the paper significantly. Support from the National Science Foundation of Switzerland, grant no. NF 200021-138216, is gratefully acknowledged.

Edited by: Florian Fusseis

Reviewed by: David Prior and Luiz Morales

\section{References}

Ardell, A. J., Christie, J. M., and Mccormick, J. W.: Dislocation images in quartz and determination of burgers vectors, Philos. Mag., 29, 1399-1411, 1974.

Avelallemant, H. and Carter, N.: Pressure dependence of quartz deformation lamellae orientations, Am. J. Sci., 270, 218-235, 1971.

Bachmann, F., Hielscher, R., and Schaeben, H.: Grain detection from $2 d$ and $3 d$ EBSD data-Specification of the MTEX algorithm, Ultramicroscopy, 111, 1720-1733, https://doi.org/10.1016/j.ultramic.2011.08.002, 2011.

Baeta, R. and Ashbee, K.: Slip systems in quartz 2. Interpretation, Am. Mineral., 54, 1574-1582, 1969.

Behrmann, J. and Mainprice, D.: Deformation mechanisms in a high-temperature quartz feldspar mylonite - evidence for superplastic flow in the lower continental-crust, Tectonophysics, 140, 297-305, https://doi.org/10.1016/0040-1951(87)90236-8, 1987.

Bergmann, R., Chan, R. H., Hielscher, R., Persch, J., and Steidl, G.: Restoration of manifold-valued images by halfquadratic minimization, Inverse Probl. Imag., 10, 281-304, https://doi.org/10.3934/ipi.2016001, 2016.

Berthe, D., Choukroune, S., and Gapais, D.: Quartz fabrics and progressive gneissification of granites by simple shear - example of the South Armorican Shear Zone, B. Mineral., 102, 265-272, 1979.

Blacic, J.: Plastic deformation mechanisms in quartz - effect of water, Tectonophysics, 27, 271-294, 1975.

Bouchez, J. L. and Pecher, A.: The Himalayan Main Central Thrust pile and its quartz-rich tectonites in Central Nepal, Tectonophysics, 78, 23-50, https://doi.org/10.1016/00401951(81)90004-4, 1981.

Cahn, J. W. and Mishin, Y.: Recrystallization initiated by lowtemperature grain boundary motion coupled to stress, Int. J. Mater. Res., 100, 510-515, https://doi.org/10.3139/146.110066, 2009.
Christie, J. and Green, H. W.: Several new slipsystems in quartz, Eos Trans. AGU, 45, p. 102, 1964.

Christie, J. M., Griggs, D. T., and Carter, N. L.: Experimental evidence of basal slip in quartz, J. Geol., 72, 734-756, 1964.

Cross, A. J., Hirth, G., and Prior, D. J.: Effects of secondary phases on crystallographic preferred orientations in mylonites, Geology, 45, 955-958, https://doi.org/10.1130/g38936.1, 2017.

DellAngelo, L. and Tullis, J.: Fabric development in experimentally sheared quartzites, Tectonophysics, 169, 1-21, https://doi.org/10.1016/0040-1951(89)90180-7, 1989.

Denbrok, S. W. J. and Spiers, C. J.: Experimental-evidence for water weakening of quartzite by microcracking plus solution precipitation creep, J. Geol. Soc., 148, 541-548, https://doi.org/10.1144/gsjgs.148.3.0541, 1991.

Doukhan, J. C. and Trepied, L.: Plasticity of quartz - crystallographic models and TEM observations, B. Mineral., 102, 138147, 1979.

Drury, M.: Defects and Processes in the Solid State: Geoscience Applications The McLaren Volume, Chap. Deformation lamellae in metals and minerals, 195-212, 1993.

Fitz Gerald, J., Boland, J., Mclaren, A., Ord, A., and Hobbs, B.: Microstructures in water-weakened single-crystals of quartz, J. Geophys. Res., 96, 2139-2155, 1991.

Fitz Gerald, J., Mancktelow, N., Pennacchioni, G., and Kunze, K.: Ultrafine-grained quartz mylonites from high-grade shear zones: Evidence for strong dry middle to lower crust, Geology, 34, 369372, https://doi.org/10.1130/G22099.1, 2006.

Fossen, H. and Tikoff, B.: The deformation matrix for simultaneous simple shearing, pure shearing and volume change, and its application to transpression transtension tectonics, J. Struct. Geol., 15, 413-422, https://doi.org/10.1016/0191-8141(93)90137-Y, 1993.

Gapais, D. and White, S.: Ductile Shear bands in a naturally deformed quartzite, Texture. Microstruct., 5, 1-17, 1982.

Gleason, G. C., Tullis, J., and Heidelbach, F.: The role of dynamic recrystallization in the development of lattice preferred orientations in experimentally deformed quartz aggregates, J. Struct. Geol., 15, 1145-1168, https://doi.org/10.1016/01918141(93)90161-3, 1993.

Halfpenny, A., Prior, D. J., and Wheeler, J.: Analysis of dynamic recrystallization and nucleation in a quartzite mylonite, Tectonophysics, 427, 3-14, https://doi.org/10.1016/j.tecto.2006.05.016, 2006.

Heard, H. C. and Carter, N. L.: Experimentally induced natural intragranular flow in quartz and quartzite, Am. J. Sci., 266, 1-42, 1968.

Heilbronner, R. and Kilian, R.: The grain size(s) of Black Hills Quartzite deformed in the dislocation creep regime, Solid Earth, 8, 1071-1093, https://doi.org/10.5194/se-8-1071-2017, 2017.

Heilbronner, R. and Tullis, J.: The effect of static annealing on microstructures and crystallographic preferred orientations of quartzites experimentally deformed in axial compression and shear, in: Deformation Mechanisms, Rheology and Tectonics: Current Status and Future Perspectives, edited by: DeMeer, S., Drury, M., DeBresser, J., and Pennock, G., Geological Society Special Publication, 200, 191-218, https://doi.org/10.1144/GSL.SP.2001.200.01.12, 2002.

Heilbronner, R. and Tullis, J.: Evolution of c axis pole figures and grain size during dynamic recrystallization: Results from ex- 
perimentally sheared quartzite, J. Geophys. Res.-Sol. Ea., 111, B10202, https://doi.org/10.1029/2005JB004194, 2006.

Hippertt, J.: Microstructures and c-axis fabrics indicative of quartz dissolution in sheared quartzites and phyllonites, Tectonophysics, 229, 141-163, https://doi.org/10.1016/00401951(94)90026-4, 1994.

Hippertt, J. and EgydioSilva, M.: New polygonal grains formed by dissolution-redeposition in quartz mylonite, J. Struct. Geol., 18, 1345-1352, https://doi.org/10.1016/S0191-8141(96)000478,1996

Hirth, G. and Tullis, J.: Dislocation creep regimes in quartz aggregates, J. Struct. Geol., 14, 145-159, https://doi.org/10.1016/0191-8141(92)90053-Y, 1992.

Hobbs, B. E.: Recrystallization of single crystals of quartz, Tectonophysics, 6, 353-401, 1968.

Hobbs, B. E.: The geological significance of microfabric, vol. Preferred orientation in deformed metals and rocks, Academic Press, New York, 1985.

Jaoul, O., Tullis, J., and Kronenberg, A.: The effect of varying water contents on the creep-behavior of heavitree quartzite, J. Geophys. Res.-Sol. Ea., 89, 4298-4312, https://doi.org/10.1029/JB089iB06p04298, 1984.

Kilian, R., Heilbronner, R., and Stunitz, H.: Quartz grain size reduction in a granitoid rock and the transition from dislocation to diffusion creep, J. Struct. Geol., 33, 1265-1284, https://doi.org/10.1016/j.jsg.2011.05.004, 2011a.

Kilian, R., Heilbronner, R., and Stunitz, H.: Quartz microstructures and crystallographic preferred orientation: Which shear sense do they indicate?, J. Struct. Geol., 33, 1446-1466, https://doi.org/10.1016/j.jsg.2011.08.005, 2011b.

Kilian, R., Heilbronner, R., Holyoke, Caleb W., I., Kronenberg, A. K., and Stunitz, H.: Dislocation creep of dry quartz, J. Geophys. Res.-Sol. Ea., 121, 3278-3299, https://doi.org/10.1002/2015JB012771, 2016.

Kjøll, H. J., Viola, G., Menegon, L., and Sørensen, B. E.: Brittle-viscous deformation of vein quartz under fluid-rich lower greenschist facies conditions, Solid Earth, 6, 681-699, https://doi.org/10.5194/se-6-681-2015, 2015.

Knipe, R. and Law, R.: The influence of crystallographic orientation and grain-boundary migration on microstructural and textural evolution in an S-C mylonite, Tectonophysics, 135, 155-169, https://doi.org/10.1016/0040-1951(87)90158-2, 1987.

Kottada, R. S. and Chokshi, A. H.: Grain boundary sliding during diffusion and dislocation creep in a Mg-0.7 pct Al alloy, Metall. Mater. Trans. A, 38A, 1743-1749, https://doi.org/10.1007/s11661-007-9190-x, 2007.

Kronenberg, A. and Tullis, J.: Flow strengths of quartz aggregates - grain-size and pressure effects due to hydrolytic weakening, J. Geophys. Res.-Sol. Ea., 89, 4281-4297, https://doi.org/10.1029/JB089iB06p04281, 1984.

Kruhl, J. H.: Prism- and basal-plane parallel subgrain boundaries in quartz: A microstructural geothermobarometer, J. Metamorph. Geol., 14, 581-589, https://doi.org/10.1046/j.15251314.1996.00413.x, 1996.

Langdon, T.: A unified approach to grain-boundary sliding in creep and superplasticity, Acta Metall. Mater., 42, 2437-2443, https://doi.org/10.1016/0956-7151(94)90322-0, 1994.

Law, R. D.: Deformation thermometry based on quartz c-axis fabrics and recrystallization microstructures: A review, J. Struct.
Geol., 66, 129-161, https://doi.org/10.1016/j.jsg.2014.05.023, 2014.

Law, R. D., Schmid, S. M., and Wheeler, J.: Simple shear deformation and quartz crystallographic fabrics - a possible natural example from the Torridon area of NW Scotland, J. Struct. Geol., 12, 29-45, https://doi.org/10.1016/0191-8141(90)900462, 1990.

Linker, M. F., Kirby, S. H., Ord, A., and Christie, J. M.: Effects of compression direction on the plasticity and rheology of hydrolytically weakened synthetic quartz crystals at atmospheric-pressure, J. Geophys. Res.-Sol. Ea., 89, 4241-4255, https://doi.org/10.1029/JB089iB06p04241, 1984.

Lister, G. S.: Fabric transitions in plastically deformed quartzites competition between basal, prism and rhomb systems, B. Mineral., 102, 232-241, 1979.

Mainprice, D. and Jaoul, O.: A transmission electron microscopy study of experimentally deformed quartzite with different degrees of doping, Phys. Earth Planet. Int., 172, 55-66, https://doi.org/10.1016/j.pepi.2008.07.009, 2009.

Mainprice, D., Bouchez, J. L., Blumfeld, P., and Tubia, J. M.: Dominant $\mathrm{c}$ slip in naturally deformed quartz - implications for dramatic plastic softening at high-temperature, Geology, 14, 819-822, https://doi.org/10.1130/00917613(1986)14<819:DCSIND>2.0.CO;2, 1986.

Mainprice, D., Bachmann, F., Hielscher, R., and Schaeben, H.: Descriptive tools for the analysis of texture projects with large datasets using MTEX: strength, symmetry and components, in: Rock Deformation from Field, Experiments adn Theory: A Volume in Honour of Ernie Rutter, edited by: Faulkner, D., Mariani, E., and Mecklenburgh, J., Conference on Rock Deformation from Field, Experiments and Theory in Honour of Ernie Rutter, Geol Soc London, London, Enland, May 30-31, 2012, Geological Society Special Publication, 409, 251-271, https://doi.org/10.1144/SP409.8, 2015.

Mancktelow, N. and Pennacchioni, G.: The influence of grain boundary fluids on the microstructure of quartz-feldspar mylonites, J. Struct. Geol., 26, 47-69, https://doi.org/10.1016/S0191-8141(03)00081-6, 2004.

Mancktelow, N. S.: Atypical textures in quartz veins from the Simplon fault zone, J. Struct. Geol., 9, 995-1005, https://doi.org/10.1016/0191-8141(87)90007-1, 1987.

McLaren, A. C. and Hobbs, B. E.: Flow and Fracture of Rocks, vol. Geophysical Monograph 16, Chap. Transmission electron microscope investigation of some naturally deformed quartzites, American Geophysical Union, 55-66, 1972.

McLaren, A. C., Cook, R. F., Hyde, S. T., and Tobin, R. C.: The mechanisms of the formation and growth of water bubbles and associated dislocation loops in synthetic quartz, Phys. Chem. Miner., 9, 79-94, https://doi.org/10.1007/BF00308151, 1983.

Menegon, L., Pennacchioni, G., Heilbronner, R., and Pittarello, L.: Evolution of quartz microstructure and c-axis crystallographic preferred orientation within ductilely deformed granitoids (Arolla unit, Western Alps), J. Struct. Geol., 30, 1332 1347, https://doi.org/10.1016/j.jsg.2008.07.007, 2008.

Menegon, L., Nasipuri, P., Stunitz, H., Behrens, H., and Ravna, E.: Dry and strong quartz during deformation of the lower crust in the presence of melt, J. Geophys. Res., 116, B10, https://doi.org/10.1029/2011JB008371, 2011. 
Morales, L. F. G., Mainprice, D., Lloyd, G. E., and Law, R. D.: Crystal fabric development and slip systems in a quartz mylonite: an approach via transmission electron microscopy and viscoplastic self-consistent modelling, in: Deformation Mechanisms, Rheology and Tectonics: Microstructures, Mechanics and Anisotropy, edited by: Prior, D., Rutter, E., and Tatham, D., Geological Society Special Publication, Geological Soc Publ House, 360, 151-174, https://doi.org/10.1144/SP360.9, 2011.

Morgan, S. S. and Law, R. D.: Unusual transition in quartzite dislocation creep regimes and crystal slip systems in the aureole of the Eureka Valley-Joshua Flat-Beer Creek pluton, California: a case for anhydrous conditions created by decarbonation reactions, Tectonophysics, 384, 209-231, https://doi.org/10.1016/j.tecto.2004.03.016, 2004.

Morrison-Smith, D. J., Paterson, M. S., and Hobbs, B. E.: Electronmicroscope study of plastic deformation in single-crystals of synthetic quartz, Tectonophysics, 33, 43-79, 1976.

Paterson, M.: The interaction of water with quartz and its influence in dislocation flow - an overview, Rheology of Solids and of the Earth, Oxford Science Publications, Oxford, 107-142, 1989.

Pennacchioni, G., Menegon, L., Leiss, B., Nestola, F., and Bromiley, G.: Development of crystallographic preferred orientation and microstructure during plastic deformation of natural coarsegrained quartz veins, J. Geophys. Res.-Sol. Ea., 115, B12, https://doi.org/10.1029/2010JB007674, 2010.

Price, J.: Preferred Orientations in Deformation Metals and Rocks: An Introduction to Modern Texture Analysis, Chap. Preferred orientations in Quartzites, Academic Press, Orlando, 385-406, 1985.

Reid, C. N.: Deformation Geometry for Materials Scientists, Pergamon Press, 1973.

Schmid, S. and Casey, M.: Complete fabric analysis of some commonly observed quartz c-axis patterns, Geophysical Monograph, American Geophysical Union, 36, 263-286, 1986.

Shigematsu, N., Prior, D. J., and Wheeler, J.: First combined electron backscatter diffraction and transmission electron microscopy study of grain boundary structure of deformed quartzite, J. Microsc.-Oxford, 224, 306-321, https://doi.org/10.1111/j.1365-2818.2006.01697.x, 2006.

Simpson, C.: Oblique girdle orientation patterns of quartz caxes from a shear zone in the basement core of the MaggiaNappe, Ticino, Switzerland, J. Struct. Geol., 2, 243-247, https://doi.org/10.1016/0191-8141(80)90056-5, 1980.

Song, W. J. and Ree, J. H.: Effect of mica on the grain size of dynamically recrystallized quartz in a quartzmuscovite mylonite, J. Struct. Geol., 29, 1872-1881, https://doi.org/10.1016/j.jsg.2007.09.011, 2007.

Stipp, M. and Kunze, K.: Dynamic recrystallization near the brittle-plastic transition in naturally and experimentally deformed quartz aggregates, Tectonophysics, 448, 77-97, https://doi.org/10.1016/j.tecto.2007.11.041, 2008.

Stipp, M., Stunitz, H., Heilbronner, R., and Schmid, S.: The eastern Tonale fault zone: a 'natural laboratory' for crystal plastic deformation of quartz over a temperature range from 250 to 700 degrees C, J. Struct. Geol., 24, 1861-1884, https://doi.org/10.1016/S0191-8141(02)00035-4, 2002.

Stipp, M., Tullis, J., and Behrens, H.: Effect of water on the dislocation creep microstructure and flow stress of quartz and implications for the recrystallized grain size piezometer, J. Geophys.
Res.-Sol. Ea., 111, B4, https://doi.org/10.1029/2005JB003852, 2006.

Stunitz, H., Thust, A., Heilbronner, R., Behrens, H., Kilian, R., Tarantola, A., and Gerald, J. D. F.: Water redistribution in experimentally deformed natural milky quartz single crystalsImplications for H2O-weakening processes, J. Geophys. Res.Sol. Ea., 122, 866-894, https://doi.org/10.1002/2016JB013533, 2017.

Sullivan, W. A. and Beane, R. J.: Asymmetrical quartz crystallographic fabrics formed during constrictional deformation, J. Struct. Geol., 32, 1430-1443, https://doi.org/10.1016/j.jsg.2010.08.001, 2010.

Thigpen, J. R., Law, R. D., Lloyd, G. E., and Brown, S. J.: Deformation temperatures, vorticity of flow, and strain in the Moine thrust zone and Moine nappe: Reassessing the tectonic evolution of the Scandian foreland-hinterland transition zone, J. Struct. Geol., 32, 920-940, https://doi.org/10.1016/j.jsg.2010.05.001, 2010.

Toy, V. G., Prior, D. J., and Norris, R. J.: Quartz fabrics in the Alpine Fault mylonites: Influence of pre-existing preferred orientations on fabric development during progressive uplift, J. Struct. Geol., 30, 602-621, https://doi.org/10.1016/j.jsg.2008.01.001, 2008.

Trepied, L. and Doukhan, J. C.: Dissociated alpha-dislocations in quartz - Influence on plastic-deformation, Phys. Status Solidi A, 49, 713-724, 1978.

Trepied, L., Doukhan, J., and Paquet, J.: Subgrain boundaries in quartz - Theoretical-analysis and microscopic observations, Phys. Chem. Miner., 5, 201-218, 1980.

Trepmann, C. A. and Stoeckhert, B.: Short-wavelength undulatory extinction in quartz recording coseismic deformation in the middle crust - an experimental study, Solid Earth, 4, 263-276, https://doi.org/10.5194/se-4-263-2013, 2013.

Trepmann, C. A., Stockhert, B., Dorner, D., Moghadam, R. H., Kuester, M., and Roeller, K.: Simulating coseismic deformation of quartz in the middle crust and fabric evolution during postseismic stress relaxation - An experimental study, Tectonophysics, 442, 83-104, https://doi.org/10.1016/j.tecto.2007.05.005, 2007.

Tullis, J.: Preferred orientation of quartz produced by slip during plane strain, Tectonophysics, 39, 87-102, https://doi.org/10.1016/0040-1951(77)90090-7, 1977.

Tullis, J.: Deformation of granitic rocks: Experimental studies and natural examples, in: Plastic Deformation of Minerals and Rocks, edited by: Karato, S. and Wenk, H. R., Reviews in Mineralogy \& Geochemistry, Mineralog Soc Amer, Min. Soc. Amer., 51, 5195, https://doi.org/10.2138/gsrmg.51.1.51, 2002.

Tullis, J., Christie, J., and Griggs, D.: Microstructures and preferred orientations of experimentally deformed quartzites, Geol. Soc. Am. Bull., 84, 297-314, 1973.

Twiss, R. J.: Some planar deformation features, slip systems, and submicroscopic structures in synthetic quartz, J. Geol., 84, 701724, 1976.

Urai, J. L., Means, W. D., and Lister, G. S.: Mineral and Rock Deformation: Laboratory Studies: The Paterson Volume, Chap. Dynamic Recrystallization of Minerals, American Geophysical Union, https://doi.org/10.1029/GM036p0161, 1986.

Vernooij, M. G. C., den Brok, B., and Kunze, K.: Development of crystallographic preferred orientations by nucleation and growth of new grains in experimentally deformed quartz single crystals, Tectonophysics, 427, 35-53, https://doi.org/10.1016/j.tecto.2006.06.008, 2006. 
Wallis, S.: Vorticity analysis and recognition of ductile extension in the Sambagawa Belt, SW Japan, J. Struct. Geol., 17, 1077-1093, https://doi.org/10.1016/0191-8141(95)00005-X, 1995.

Wenk, H. R. and Christie, J. M.: Comments on the interpretation of deformation textures in rocks, J. Struct. Geol., 13, 1091-1110, https://doi.org/10.1016/0191-8141(91)90071-P, 1991.
White, S.: Dislocation structures responsible for optical effects in some naturally deformed quartzes, J. Mater. Sci., 8, 490-499, 1973.

Xypolias, R.: Some new aspects of kinematic vorticity analysis in naturally deformed quartzites, J. Struct. Geol., 31, 3-8, https://doi.org/10.1016/j.jsg.2008.09.009, 2009. 